

\section{DISCLAIMER}

This report was prepared as an account of work sponsored by an agency of the United States Government. Neither the United States Government nor any agency Thereof, nor any of their employees, makes any warranty, express or implied, or assumes any legal liability or responsibility for the accuracy, completeness, or usefulness of any information, apparatus, product, or process disclosed, or represents that its use would not infringe privately owned rights. Reference herein to any specific commercial product, process, or service by trade name, trademark, manufacturer, or otherwise does not necessarily constitute or imply its endorsement, recommendation, or favoring by the United States Government or any agency thereof. The views and opinions of authors expressed herein do not necessarily state or reflect those of the United States Government or any agency thereof. 


\section{DISCLAIMER}

Portions of this document may be illegible in electronic image products. Images are produced from the best available original document. 
The facilities of Argonne National Laboratory are owned by the United States Government. Under the terms of a contract (W-31-109-Eng-38) between the U. S. Energy Research and Development Administration, Argonne Universities Association and The University of Chicago, the University employs the staff and operates the Laboratory in accordance with policies and programs formulated, approved and reviewed by the Association.

\section{MEMBERS OF ARGONNE UNIVERSITIES ASSOCIATION}

The University of Arizona Carnegie-Mellon University Case Western Reserve University The University of Chicago University of Cincinnati Illinois Institute of Technology University of Illinois Indiana University Iowa State University The University of Iowa
Kansas State University The University of Kansas Loyola University Marquette University Michigan State University The University of Michigan University of Minnesota University of Missouri Northwestern University University of Notre Dame
The Ohio State University

Ohio University

The Pennsylvania State University Purdue University

Saint Louis University

Southern Illinois University The University of Texas at Austin Washington University

Wayne State University

The University of Wisconsin

NOTICE

This report was prepared as an account of work sponsored by the United States Government. Neither the United States nor the United States Energy Research and Development Administration, nor any of their employees, nor any of their contractors, subcontractors, or their employees, makes any warranty, express or implied, or assumes any legal liability or responsibility for the accuracy, completeness or usefulness of any information, apparatus, product or process disclosed, or represents that its use would not infringe privately-owned rights. Mention of commercial products, their manufacturers, or their suppliers in this publication does not imply or connote approval or disapproval of the product by Argonne National Laboratory or the U. S. Energy Research and Development $\Lambda$ dministration.

Printed in the United States of America Available from

National Technical Information Service

U. S. Department of Commerce 5285 Port Royal Road

Springfield, Virginia 22161

Price: Printed Copy Microfiche $\$ 3.00$ 
Distribution Category:

ANL-77-58

ARGONNE NATIONAL LABORATORY

9700 South Cass Avenue

Argonne, Illinois 60439

SCINTILLATION SPECTROMETER SYSTEM FOR MEASURING

FAST-NEUTRON SPECTRA IN BEAM GEOMETRY

by

G. G. Simons and J. M. Larson

Applied Physics Division

Idaho. Falls, Idaho

and

R. S. Reynolds

Mississippi State University

P. O. Drawer NE

Mississippi State, Mississippi 39762

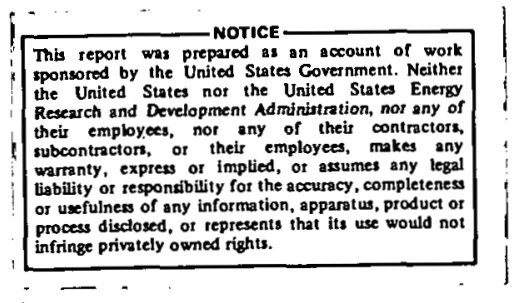

May 1977 
ABSTRACT . . . . . . . . . . . . . . . . . . 1

I. INTRODUCTION . . . . . . . . . . . . . . . 1

II. SPECTROMETER SYSTEM . . . . . . . . . . . . 2

A. Detector Assembly ................ . 3

1. Detector Design . . . . . . . . . . . 3

2. Detector Mounting . . . . . . . . . . 3

3. Detector Operation............... . 3

4. Preamp1ifier Circuit Design ............ 8

5. Gamma-neutron Pulse Shaping (GNS) Circuit.... 8

B. Associated Electronics. . . . . . . . . . 11

1. System Pulse Shaping and Timing . . . . . . . 11

2. Pulse Shape Discriminator (PSD) Module. . . . . 12

3. Double Delay-line Fast Amplifier. . . . . . . 13

III. SPECTROMETER EVALUATION . . . . . . . . . . . 15

A. ${ }^{22} \mathrm{Na}$ Gamma-ray Source Data. . . . . . . . . 15

B. PuBe Neutron Spectra. . . . . . . . . . . 19

C. ${ }^{252}$ Cf Neutron Spectra . . . . . . . . . . . 19

IV. RADIATION SHIELD/COLLIMATOR ASSEMBLY . . . . . . . . . 23

V. ZPPR FAST NEUTRON LEAKAGE MEASUREMENTS . . . . . . . . . 27

REFERENCES . . . . . . . . . . . . . . . . . . 30 


\section{LIST OF FIGURES}

No.

Title

$\underline{\text { Page }}$

1 Block Diagram of Spectrometer System. . . . . . . . . . . 2

2 Typica1 Assoclated and Auxiliary Electronics Located in the Spectrometer Laboratory . . . . . . . . . . . . . . 4

3 Voltage Divider String. . . . . . . . . . . . . . 5

4 Detector Assembly . . . . . . . . . . . . . 6

5 Preamplifier Circuit Diagram. . . . . . . . . . . . 9

6 Gamma-Neutron Shaping (GNS) Circuit Diagram and Typical

Pulse Shapes. . . . . . . . . . . . . . 10

7 System Pulse Shaping and Timing . . . . . . . . . . . 12

8 Pulse Shape Discriminator (PSD) Circuit Diagram . . . . . . . 13

9 Pulse Shape Discriminator (PSD) Circuit Diagram . . . . . . . . 14

10 Pulse Shape and Timing in the PSD Module. . . . . . . . . 15

11 Double Delay Line Fast Amplifier Circuit Diagram. . . . . . 16

12 Gamma-Ray Rejection Ratio as a Function of Countrate. . . . . 17

13 High Energy Portion of the ${ }^{22} \mathrm{Na}$ Induced Pulse Height Distribution. . . . . . . . . . . . . . . 18

14 PuBe Source Neutron Spectrum Measured under Ideal Geometry Conditions. . . . . . . . . . . . . . . 20

15 Intercomparison of ${ }^{252}$ Cf Neutron Spectra Measured with Different Spectrometers and Different Sourccs . . . . . . . . ??

16 Schematic Drawing of Radiation Shield . . . . . . . . . . 24

17 Schematic Drawing of Collimator Insert for the Radiation Shield... . . . . . . . . . . . . . . . 25

18 Shield/Collimator In Llie ZPPR Cell. . . . . . . . . . . . 26

19 Compartson of ${ }^{252}$ Cf Neutron Spectra Mcasured with the Detertor Located Inside and Outside the Shield/Collimator. . . . . . . 


\section{LIST OF FIGURES (contd.)}

No.

20. Measured Neutron Spectrum from the Inner Core Zone Normalized to Unity Area from 1.4 to $7.8 \mathrm{MeV}$. . . . . . . . . . .

21 Measured Neutron Spectrum from the Outer Core Zone Normalized to Unity Area from 1.4 to $7.8 \mathrm{MeV}$. . . . . . . . . . .

22 Measured Neutron Spectrum from the Radial Blanket Zone Normalized to Unity Area from 1.4 to $7.8 \mathrm{MeV}$. . . . . . . .

I Approximate PuBe Neutron Spectrum Maxima (Mev) . . . . . . 


\title{
SCINTILLATION SPECTROMETER SYSTEM FOR MEASURING FAST-NEUTRON SPECTRA IN BEAM GEOMETRY
}

by

G.G. Simons, R.S. Reynolds, and J.M. Larson

\begin{abstract}
A high-energy liquid-organic scintillation spectrometer system is described. This spectrometer was developed to measure neutron spectra in extracted beams from zero-power fast reactors. The highly efflcient NE-213 scintillation solution was used as the neutron detection medium. Identification and removal of gamma-rayinduced events was accomplished using electronic pulse shape discrimination. Instrumentation used to process the discrete pulses stemming from neutron and gamma-ray interactions, within the scintillation solution, is described in detail. Evaluation of the system's performance is discussed for a gamma-ray discrimination ratio of nominally 1000:1, a total countrate of $3000 \mathrm{cps}$, and a dynamic range corresponding to neutron energies from 1 to $10 \mathrm{MeV}$. Operation above $10 \mathrm{MeV}$ is certainly possible. However, since the neutron flux above $10 \mathrm{MeV}$ was negligible in the radiation fields of interest in this work, the operating characteristics of the spectrometer were not evaluated above $10 \mathrm{MeV}$. Neutron spectra are reported for extracted beam measurements made on ZPPR assembly 4 , phase 2 .
\end{abstract}

\section{INTRODUCTION}

A variety of fast-neutron absolute flux and spectra measuring instruments have been developed and their operating characteristics documented: Most of these rely on the proton-recoil phenomenon. Accurate measurements are possible over a wide energy range since their neutron response depends upon the well-known ${ }^{1} \mathrm{H}(n, n)$ cross section. The main types of proton-recoil detectors are 1) the telescope which uses a thin-solid polyethylene radiator, 2) the proportional counter containing hydrogen and methane gases, and 3) either solid stilbene or liquid organic scintillators. The telescope fulfills the need for measuring absolute flux in monoenergetic neutron.fields [1]. Gas-filled proportional counters are routinely used to measure spectra from nominally $1 \mathrm{keV}$ to above $1 \mathrm{MeV}$ inside the Argonne National Laboratory and AEE Winfrith Zero Power Reactors [2,3]. They have also been used to measure the fission spectra from ${ }^{2} 3{ }^{9} \mathrm{Pu}, 235 \mathrm{U}$, and ${ }^{252} \mathrm{Cf}$ from 0.104 to $9.5 \mathrm{MeV}$ [4]. Extracted beam and/or encapsulated neutron source spectra have been measured above $1 \mathrm{MeV}$ using stilbene [5-7] and liquid organic scintillators $[8-12]$.

To expand the energy range significantly above $1 \mathrm{MeV}$, for experiments performed at the Argonne Zero Power Plutonium Reactor (ZPPR) and the Argonne Fast Source Reactor [13], a fast-neutron spectrometer using an NE-213 1iquid urganic scintillator detector was constructed. The NE-213 liquid scintillator was selected because of its proven performance in other fast-neutron 
detector assemblies. This scintillator is very efficient over the neutron energy range from 1 to above $14 \mathrm{MeV}$, does not exhibit nonisotropic behavior characteristic of stilbene [14], and is amenable to pulse-shape-discrimination [8]. Also, since the scintillator is a liquid, detectors containing $\mathrm{NE}-213$ can be fabricated in various sizes and shapes to optimize performance in a specific radiation environment. However, accurate knowledge is required of the response and efficiency for each type of detector configuration. This tends to discourage the assemblage of a large number of unique detectors. The NE-213 detector used with the spectrometer described below is similar to detectors previously calibrated by Simons et al [15] and Verbinski et al [8].

This fast-neutron spectrometer uses pulse-shape rejection based upon the pulse-shape differences between neutron and gamma-ray induced events. Several new electronic circuits were designed to perform specific functions of pulse shaping, timing, and amplification. These were integrated with commercially available electronic modules to form the total system. Only the unique features of this system are described in detail. Features common to all NE-213 spectrometers will be presented only if this information is required to understand the operation of the system being described. In addition to a description of the experimental equipment, an evaluation of the epectrometer's operation and measured reactor spectra are presented.

\section{SPECTROMETER SYSTEM}

The high energy spectrometer is composed of two major segments -- the detector assembly and the modules comprising the associated electronics. As shown in the block diagram of Fig. 1, the complete system consists of

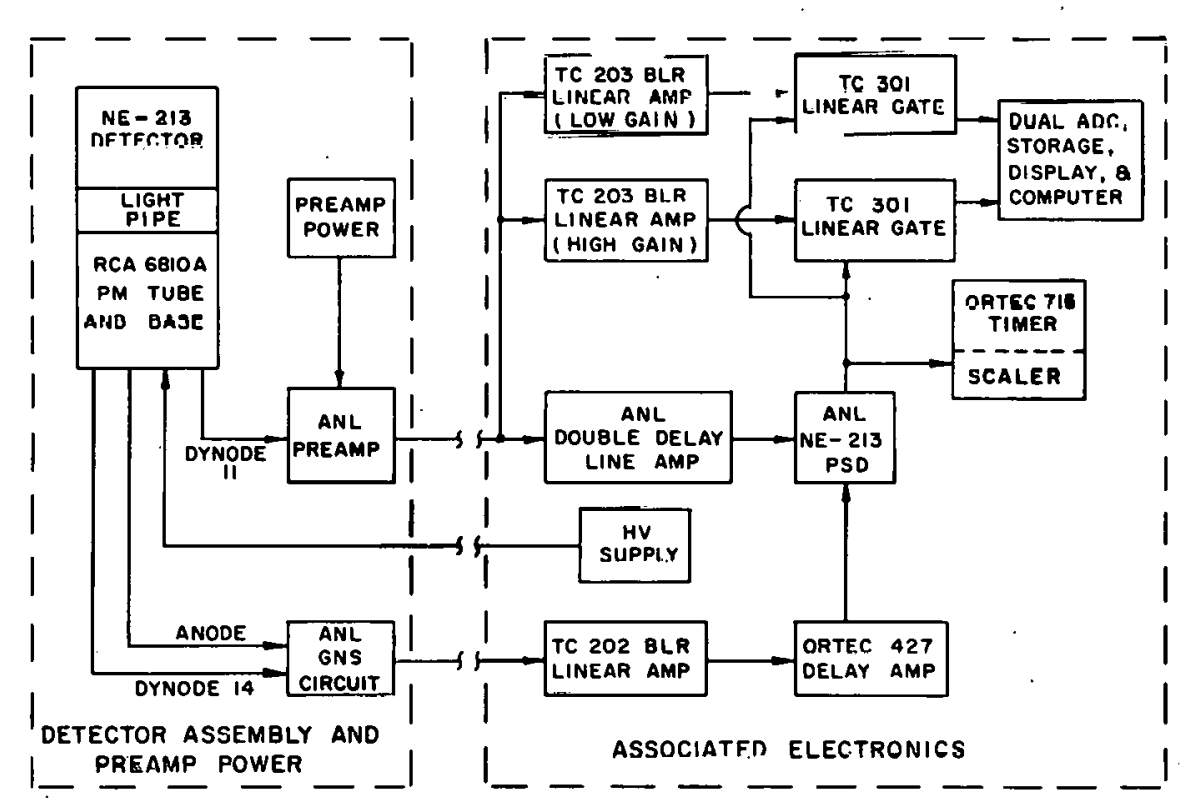

Fig. 1. Block Diagram of Spectrometer System 
the detector assembly, power supplies, signal conditioning electronics, timing electronics, and a computer-based dual pulse-height analyzer. During an experiment, the detector assembly is physically located in the neutron field whose spectrum is to be measured. Output pulses from the preamplifier and the gamma-neutron shaping (GNS) circuit are transferred to the associated electronics through a long ( $46 \mathrm{~m}$ ) $93 \mathrm{ohm}$ terminated cable. The associated electronics are housed in the spectrometer laboratory as shown in Fig. 2 . Therefore, once the detector assembly is in position (and the GNS circuit adjusted) the systems operation can be optimized and maintained without entering the radiation field.

\section{A. Detector Assemb1y}

The detector assembly consists of the detector, light pipe, photomultiplier (PM) tube, PM-tube voltage divider string (see Fig. 3), magnetic shield, linear signal preamplifier, and GNS circuit. As shown in Fig. 4, the detector assembly height was minimized by recessing the PM tube and appropriately locating the preamplifier and GNS circuit cards about the circumference of the PM tube. The flat base design assured that the detector remained in the desired vertical position. During operation, with all side panels closed, dry compressed air was flowed through the base. Thus a constant, cool, temperature was maintained around the PM tube base. This minimized temperature related PM-tube gain changes.

\section{Detector Design}

The detector is the NE-213 scintillation solution*, prepared from purified xylene, naphthalene, activators, and POPOP spectrum shifter. It was deoxygenated and encapsulated under nitrogen (to prevent ion quenching by oxygen) in a low-background glass cell. A standard V-type cylindrical cell $50.8 \times 50.8 \mathrm{~mm}$, without white reflector paint was used. The cell contained $96.7 \mathrm{ml}$ of solution at $20^{\circ} \mathrm{C}$.

\section{Detector Mounting}

The NE-213 detector was optica11y coupled to a 6.35-mm-thick lucite light pipe and an RCA 6810-A PM tube. Aluminum foil was then placed over the detector and light pipe extending nominally $25 \mathrm{~mm}$ onto the PM tube. Black electrician's tape was wrapped around the foil and the PM tube to isolate the components from ambient light. This configuration has been shown to possess reduced response variation and improved resolution relative to detectors coated with white reflector paint and without a light pipe [8]. Visual inspection of the optical couplings was also possible since the reflector foil was added after attaching the detector to the light pipe and PM tube. The PM tube was surrounded by a magnetic shield.

\section{Detector Operation}

The NE-213 scintillation solution responds indirectly to fast neutrons through both recoil proton and carbon nuclei scattering interactions. Unfortunately NE-213 responses are not limited to neutron interactions; the

\footnotetext{
* Nuclear Enterprises Inc., 935 Terminal Way, San Carlos, Calitornia.
} 


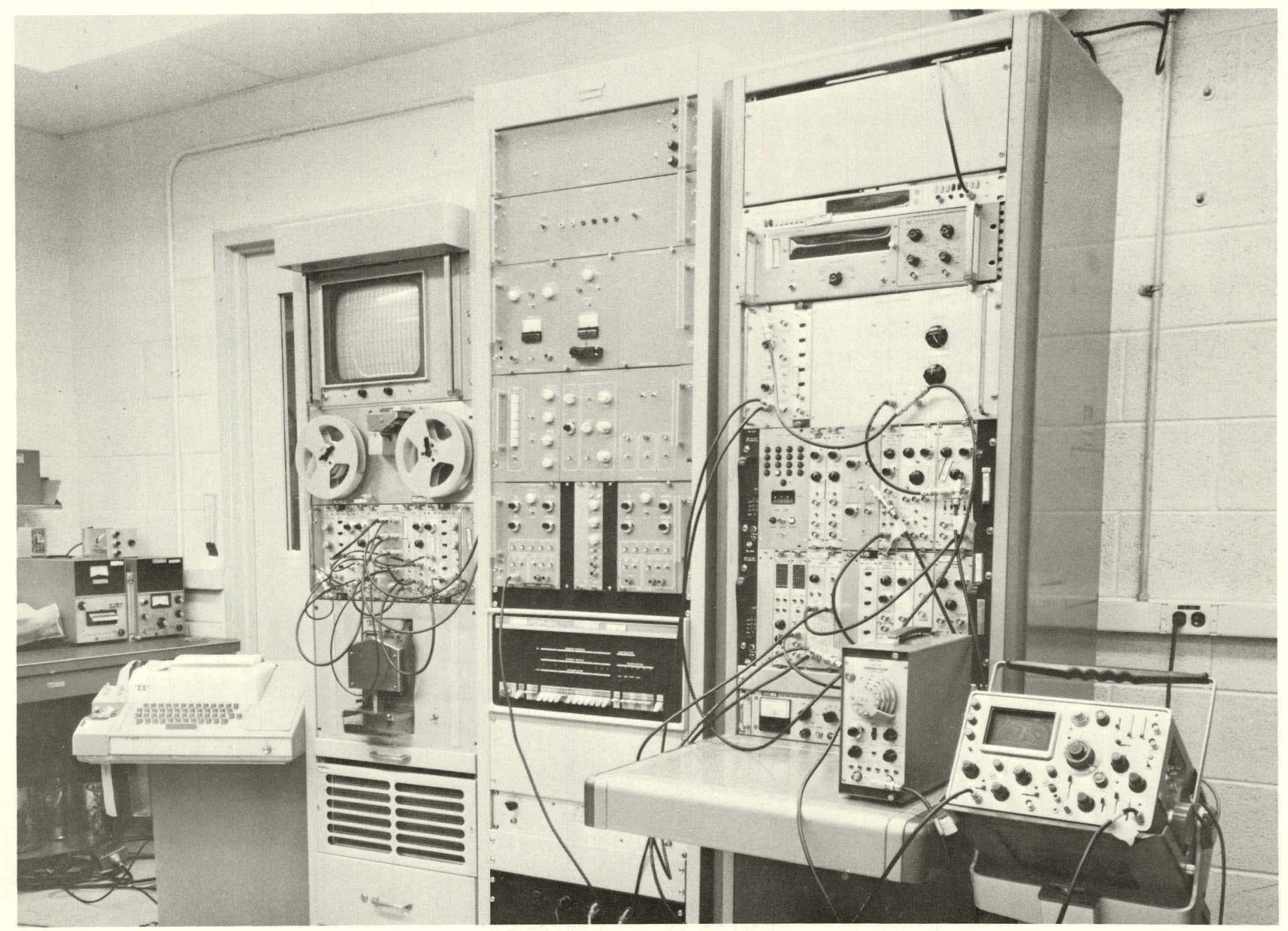

Fig. 2. Typical Associated and Auxiliary Electronics Located in the Spectrometer Laboratory. ANL Neg. No. 103-B11417. 


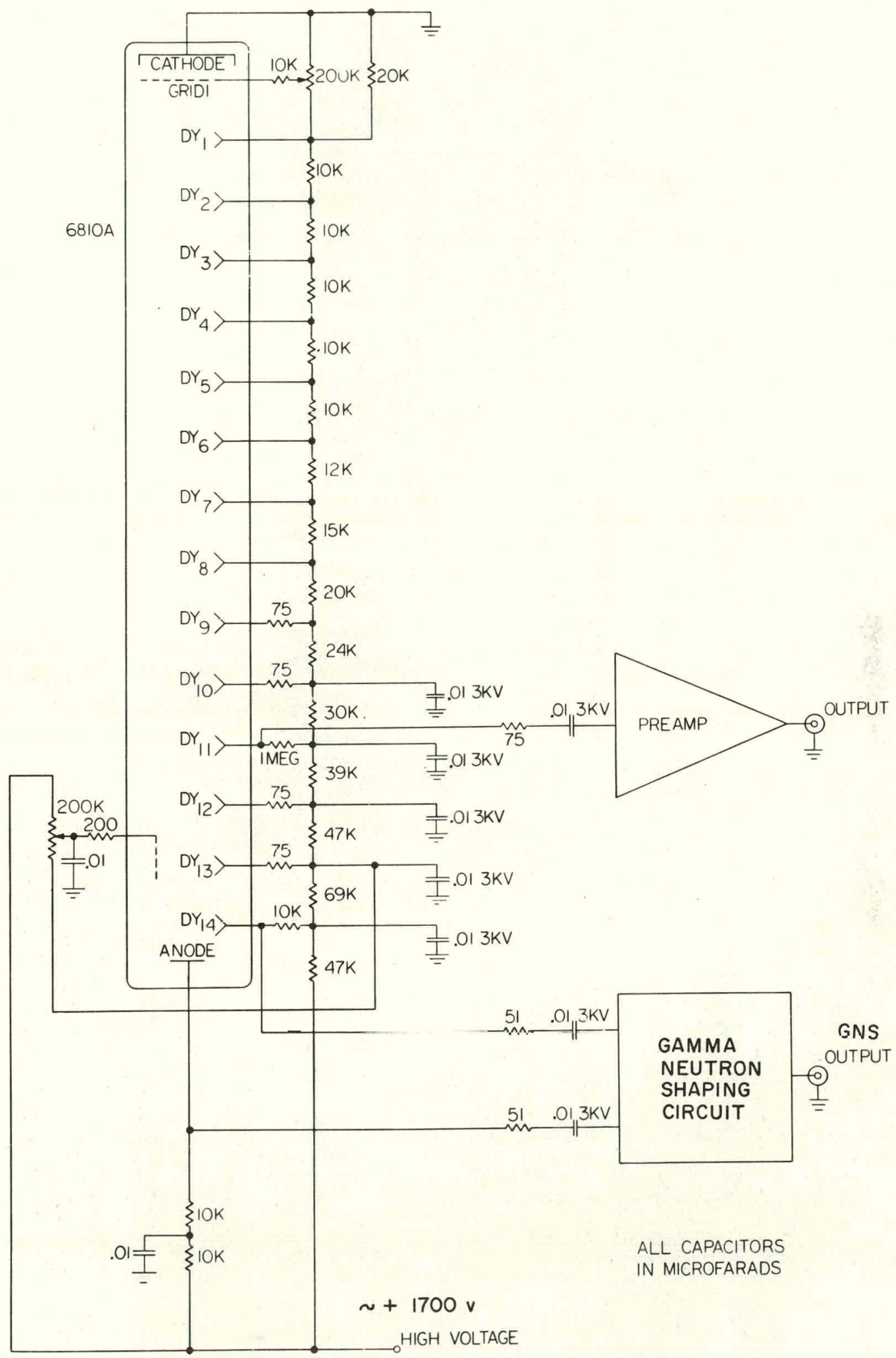

Fig. 3. Voltage Divider String 


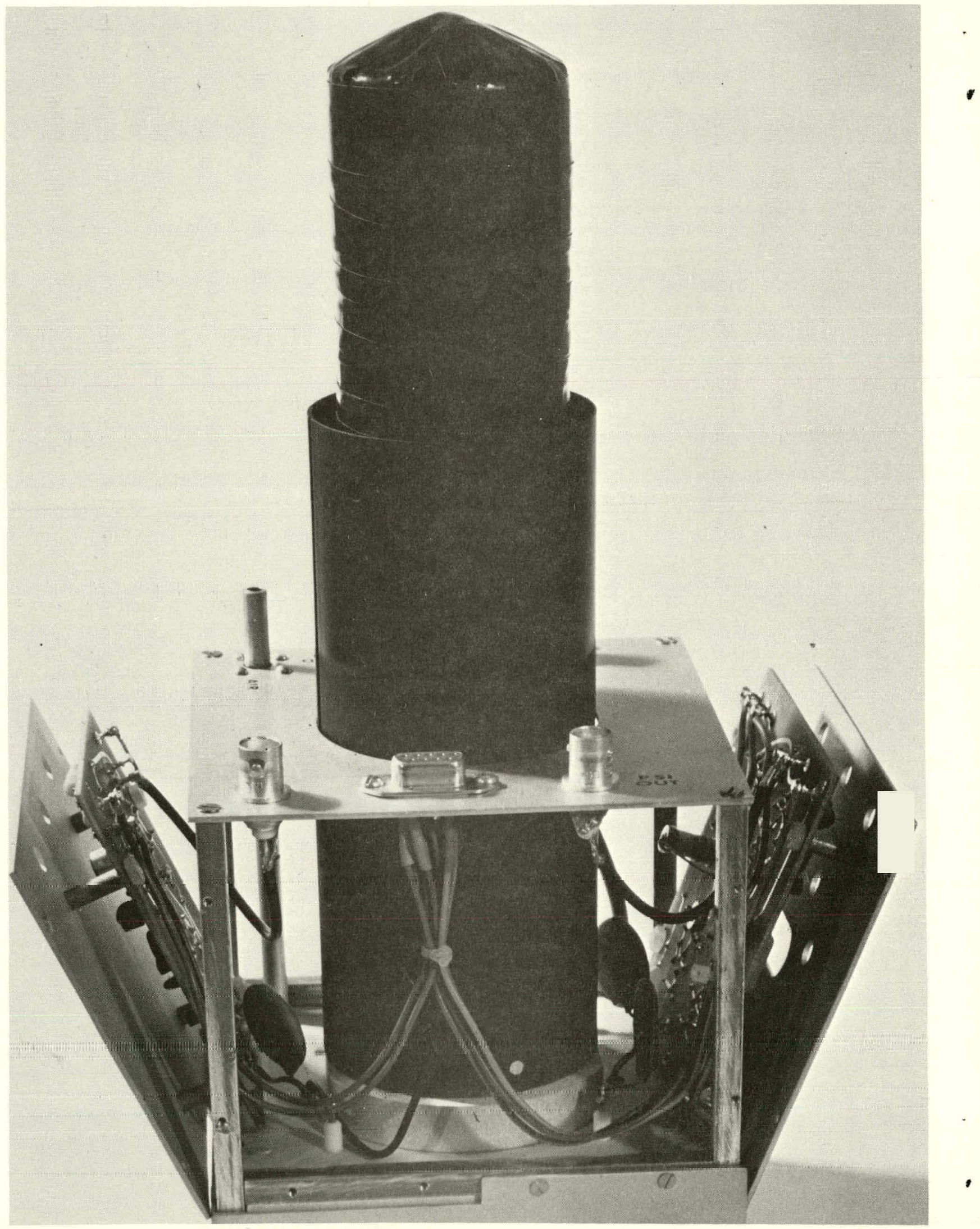

Fig. 4. Detector Assembly 
scintillator solution also produces light pulses when excited by electrons resulting from gamma-ray interactions in the solution. It is possible, however, to distinguish electronically between neutron and gamma-ray responses by pulse-shaping techniques. Light pulses produced in the NE-213 scintillator solution by protons, alpha particles (resulting respectively from neutronhydrogen and neutron-carbon interactions) and electrons (resulting from gammaray interactions) are subsequently detected and amplified by the PM tube. Signals from the PM tube are further amplified, shaped, and sorted to distinguish between neutron and gamma-ray originated pulses.

Although the carbon inelastic reactions will not contribute greatly to the total response of the NE-213 scintillator, their presence and the other factors [16] cause the response of the NE-213 scintillation solution to be non-rectangular. Monoenergetic neutron responses have been measured and/or computed using a complex model $[4,15,17,18]$. Following determination of these responses, various mathematical models have been used to obtain an estimate of the energy spectrum from measured pulse height data [19-21]. A preferable method of analysis would be one based upon neutron interaction kinematics. No exact kinematics model exists. However, approximate models have been developed which give good estimates of the neutron spectrum [22].

Problems associated with the use of the NE-213 scintillation solution are further aggravated, as noted above, due to the presence of gamma rays in the radiation field. The dominant gamma-ray interaction in the $\mathrm{NE}-$ 213 scintillation solution is Compton scattering. Since the incident gamma rays may lose a variable fraction of their energy, $E_{\gamma}$, during a Compton event, the response of the detector to gamma rays is a smooth, rather featureless, pulse-height distribution extending from zero to a maximum value slightly greater than. the maximum electron energy of

$$
E_{c}=\frac{E_{\gamma}}{1+\frac{m_{o} c^{2}}{2 E_{\gamma}}} .
$$

If the detection system exhibited perfect resolution the maximum pulse height would be at exactly $E_{C}$; however, due to instrument broadening of the pulse shape, this energy is generally considered to correspond to the pulse height near $50 \%$ intensity at the rather broad Gaussian shaped "tail" of the response $[8,23]$.

A very useful characteristic of the NE-213 detector is its linear response to electrons of energy greater than $0.150 \mathrm{MeV}$ [25]. This feature allows readily available monoenergetic gamma-ray sources to be used to calibrate the pulse-height distribution relative to Compton electron energies.

Differences in observed NE-213 scintillation solution pulse shapes following either neutron or gamma-ray excitation allows the scintillation solution to be used in a combined neutron and gamma-ray field. The pulse shape following excitation is the result of fast- and slow-decay components in the scintillator [24]. The fast component is due to the decay of the initial solvent excitation. The second type of decay consists of complex jon recombination reactions with a much longer decay time. The fast and slow 
pulse components have different reaction mechanisms; these mechanisms are dependent upon the nature of the ionizing particle. Observed spectfic iontzation for protons in the NE-213 solution is greater than that for electrons, and further, the proton pulse has a greater ratio of slow to fast pulse decay components.

\section{Preamplifier Circuit Design}

The preamplifier, connected to dynode 11 of the PM tube, is a modification of the charge sensitive preamplifier designed for the proton-recoil proportional-counter spectrometer [25]. The preamplifler, shown schematically in Fig. 5, isolates the $11^{\text {th }}$ dynode of the PM tube from external loading and provides a stable charge gain for the linear signal. Its gain is determined by the feedback capacitor $C_{f}$. In this application, $C_{f}$ should have a value between 90 and 120 pfd.

\section{Gamma-neutron Pulse Shaping (GNS) Circuit}

The basic design of the GNS cirroit, shown in Fig. 6, is an adaptation of a technique developed by Forte et al [26]. Our technique differs from the earlier design in that RL differentiation and RC pulse stretching are combined in the anode side of the circuit. This provides improved pulse shape matching and cancellation of the shaped anode pulae and the fast component of the $14^{\text {th }}$ dynode pulse. Also, the GNS circuit is isolated from the PM tube by common base transistors $Q_{1}$ and $Q_{2}$. This results in a low impedance termination ( $<50$ ohms) of the PM tube's last dynode and anode. This type of connection optimizes the PM tube's linear response by preventing tube saturation and the accompanying pulse distortion that occurs when the PM tube saturates. With this connection the peak anode and dynode voltages are no greater than 5 vnlts for the marimum signal peaks:

The GNS circuit performs the following pulse shaping operations. The current from the $14^{\text {th }}$ dynode yields the voltage pulse $V_{1}$ acrnss resistor $\mathrm{R}_{1}$ (refer to Fig. 6). The dashed line represents the neutron induced event and the solid line the gamma-ray induced event. Hence, the $V_{1}$ pulse decays rapidly if generated by a gamma ray, or more slowly if generated by a neutron. Corresponding current pulses (stemming from the same event) from the anode are 1) passed through transistor $Q_{2}, 2$ ) differentiated by inductor $L_{1}$, and 3) clamped by dlode CR-1. A narrow pulse, $V_{2}$, results. This pulse paecco through diode $\mathrm{CR}-2$ charging the variable capacitor $\mathrm{C}_{1}$, thus generating the voltage $V_{3}$, which is applied to resistor $R_{4}$. The decay of $v_{3}$ is determined by capacitor $C_{1}$ and resistor $R_{2}$. Capacitor $C_{1}$ is adjusted until the decay rate of the voltage pulse $V_{3}$ approximates the decay rate of the dynode pulse $V_{1}$ when the detector is exposed only to gamma rays.

The output pulse of the shaping circuit is obtained by summing the dynode and anode pulses at the junction of $R_{3}$ and $R_{4}$. The shape of the output pulse formed by this summation represents the difference between the pulse shape of the dynode pulse and the fixed shape of the pulse generated by the anode circuit. Discrimination of gamma-ray induced events is achieved by. adjusting potentiometer $R_{1}$ until the best possible cancellation of dynode and anode pulses is obtained at the summing junction. With proper adjustment, cancellation occurs at the summing junction for pulses resulting from gammainduced events in the NE-213 scintillator and no output is obtained. However, 


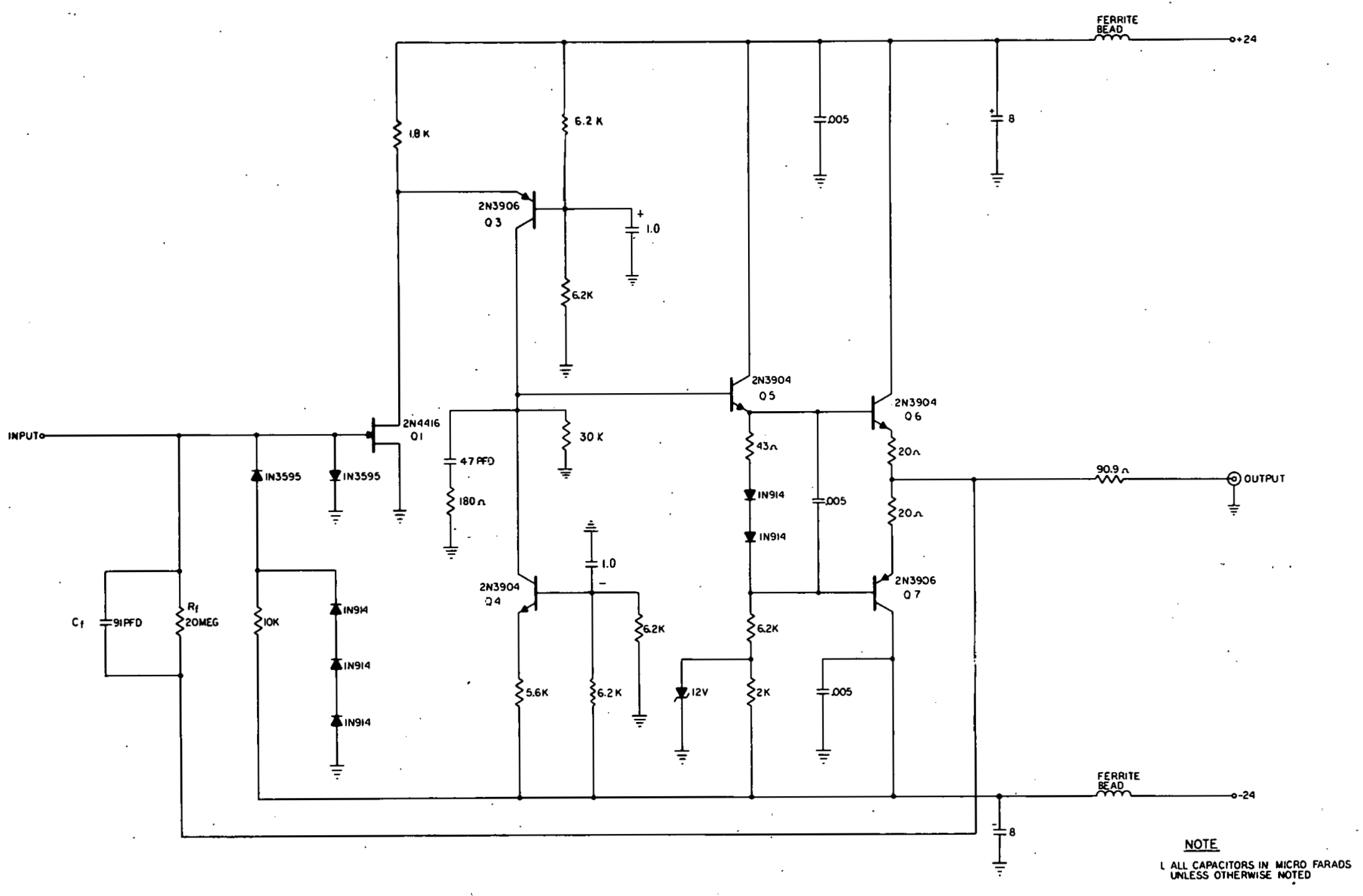

Fig. 5. Preamplifier Circuit Diagram. ANL Neg. No. 103-B11517. 


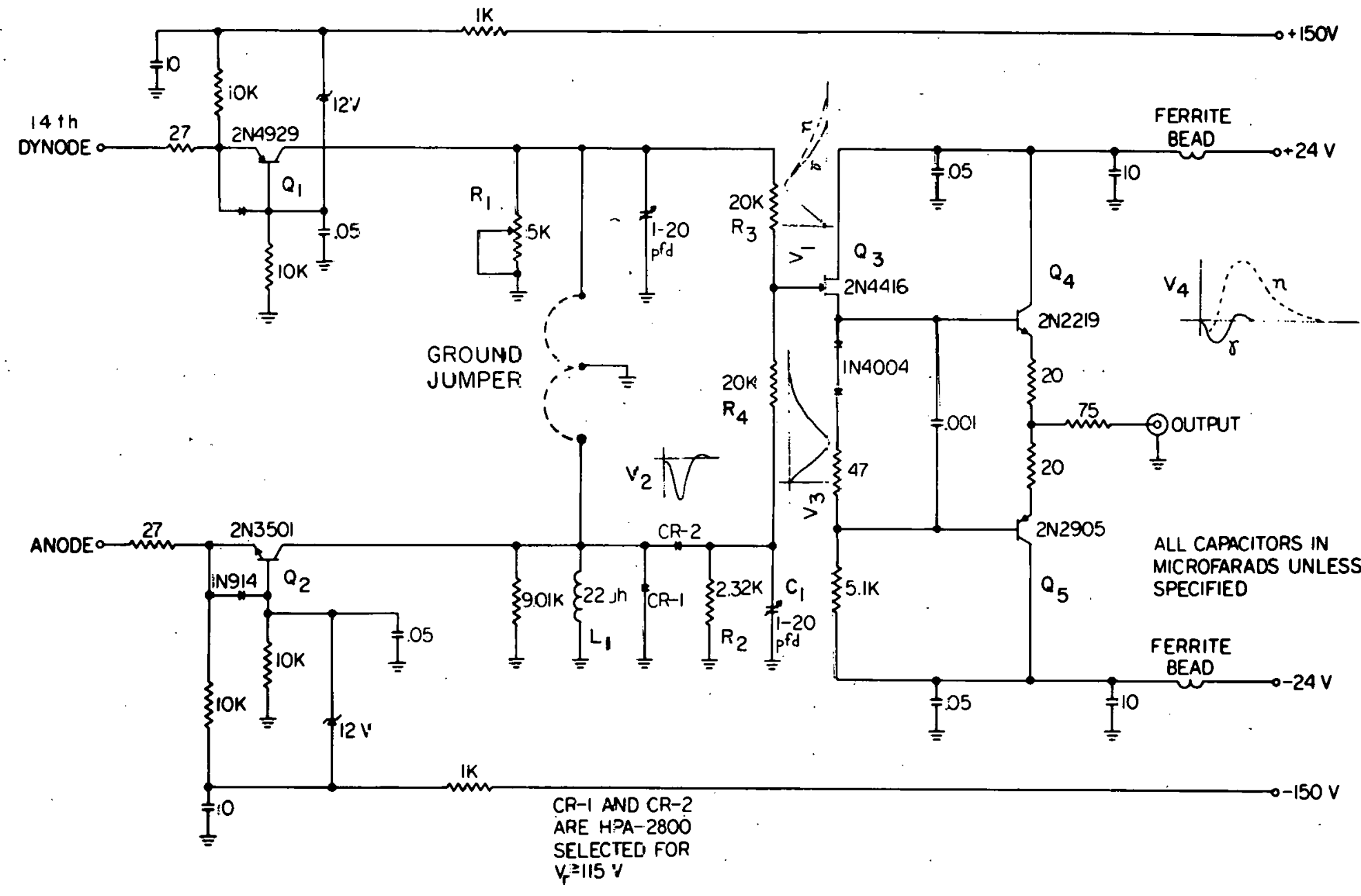

Fig. 6. Camma-Neutron Shafing (GNS) Circuit Diagram and Typical

Fulse Shapes. ANL Neg. No. 103-AIl378 Kev. I. 
for neutron-induced events, the decay at pulse $v_{1}$ is longer than that of $v_{3}$ and incomplete cancellation occurs, with the consequence that a positive component of voltage is obtained at the summing junction of $R_{3}$ and $R_{4}$. The output voltage at the junction of $R_{3}$ and $R_{4}$ passes through the unity gain buffer amplifier, comprised of FET $Q_{3}$ and transistors $Q_{4}$ and $Q_{5}$, thus generating the output pulse $\mathrm{V}_{4}$ in Fig. 6. The dashed-wave form of this pulse characterizes the pulse shape obtained for neutron events, and the solid-wave form characterizes the shape obtained for gamma-ray events.

It should be noted that complete cancellation of pulses does not occur for gamma-induced events primarily because of imperfect shaping of the leading edge of anode pulse, $V_{3}$. This imperfection has a direct effect on the gamma-ray rejection ratio of the system and therefore the lower energy neutron response of the system. For high energy gamma-rays the positive, $v_{4}$, pulse overshoot 1ncreases in magnitude and its shape is very similar to the lower energy neutron-induced pulse. Consequently, the discrimination circuit must be adjusted in such a manner so as to minimize gamma-ray induced pulse height analysis while simultaneously preserving the lower energy neutron response of the system.

It was stated in Section II.A.2. without explanation why, that an RCA 6810-A PM tube was used in conjunction with the GNS circuit. Several tubes were evaluated. The RCA 6810-A tube was selected instead of a more recent PM tube because of its high output current capability. Furthermore, the gain of this tube could be set so that the peak heights of voltage pulses $\mathrm{V}_{1}$ and $\mathrm{V}_{3}$ approached 120 volts. A large dynamic range was thus provided over which the non-linearities of diode CR-2 remained negligible.

Transistors $Q_{3}, Q_{4}$, and $Q_{5}$ comprise a fast responding unity gain output driver that has very low input capacitance and a low output impedance suitable for driving coaxial cable.

\section{B. Associated Electronics}

The associated electronics, shown in Fig. 1, consist of commercial modules and two AP-West (the Argonne Applied Physics Division's Idaho facility) designed circuits. Since the specifications of each commercial module are readily available, only the funtions which these modules perform will be mentioned. As described in Section II.A.5., the shape of the GNS output signal uniquely defines the type of radiation which produced the scintillation in the NE-213 detector. Extraction of this information into a usable form is accomplished by the timing and gate generating circuitry in the AP-West designed PSD circuit. The AP-West double delay-line fast amplifier was designed to allow optimum pulse timing of the linear signal from the $11^{\text {th }}$ dynode. General operation of the associated electronics is explained in the next section. Additional details of the operation and design of the PSD and fast amplifier are presented in Sections II.B.2. and II.B.3. respectively.

\section{System Pulse Shaping and Timing}

Pulse shaping and timing operations of the spectrometer system are represented in Fig. 7. The dashed line in Fig. 7-A represents a neutroninduced pulse at Llie GNS circuit output. In coincidence with this pulse, is a linear signal drawn from the $11^{\text {th }}$ dynode of the PM tube and pre-amplified 


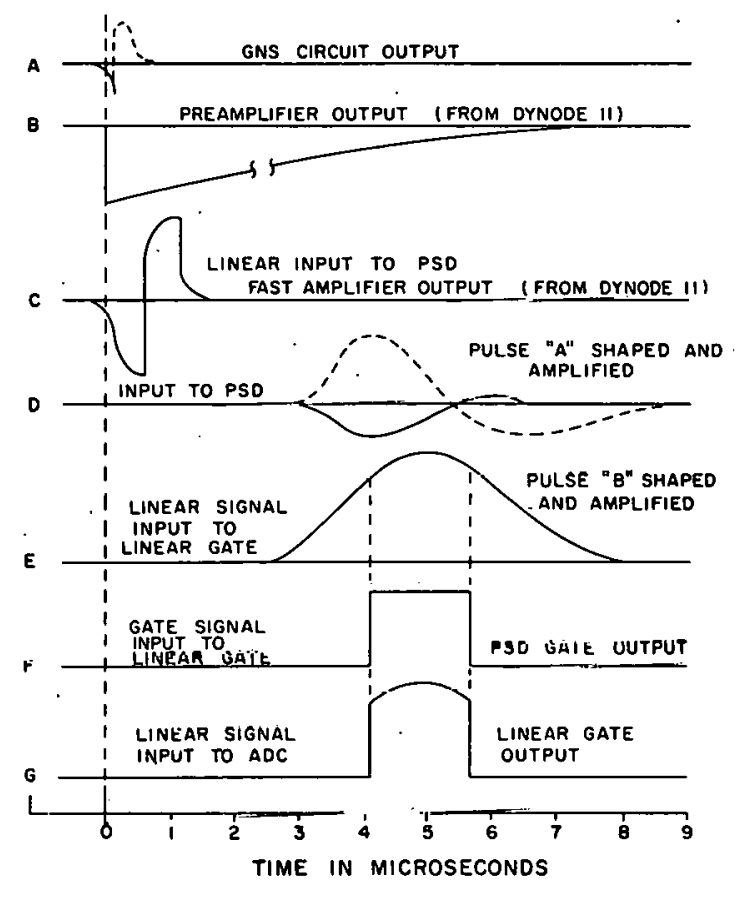

F1g. 7. System Pulse Shaping
and Timing

to yield the pulse shown in Fig. 7-B. This linear signal io clippel by the double-lelay line amplifier, and the crossover point of the resulting pulse, shown in Fig. 7-C, is used as a rcfcrence puint for the timing in the PSD module. In addition, the linear signal is ruuted to two TC 203 BLR linear amplifiers where the pulse is shaped as shown in Fig. 7-E. The GNS output (Fig. 7-A) is shaped by a TC 202 BLR linear amplifier and delayed by an ORTEC 427 delay amplifier (with a gain of one) to yield the pulse shown in Fig. 7-D. This pulse has a positive leading edge (dashed line) for neutron induced events and a negative leading edgp (snlid linc) for ganmu-ray induced events. If the pulse shown in Fig. 7-D is positive, a gating pulse shown in Fig. 7-F is generated which admits the central portion of the two TC 203 BLR amplifier outputs to the $\mathrm{ADC}$ input. A typical $\mathrm{ADC}$ input for a neutron induced pulse is shown in Fig. 7-G. Dual ADCs are used to simultaneously accumulate data at two different gain settings. The unfolding code used, FÉRDOR $[19,27]$, accepts input data in this form.

\section{Pulse Shape Discriminator (PSD) Module}

Gamma-neutron discrimination is accomplished in the PSD module (see Figs. 8 and 9) by examining the shape of the output pulse from the GNS circuit. In general, the PSD functions by determining if those pulses go positive after a specified time interval following the time reference. The time reference is at the crossover of the double clipped linear pulse. The 


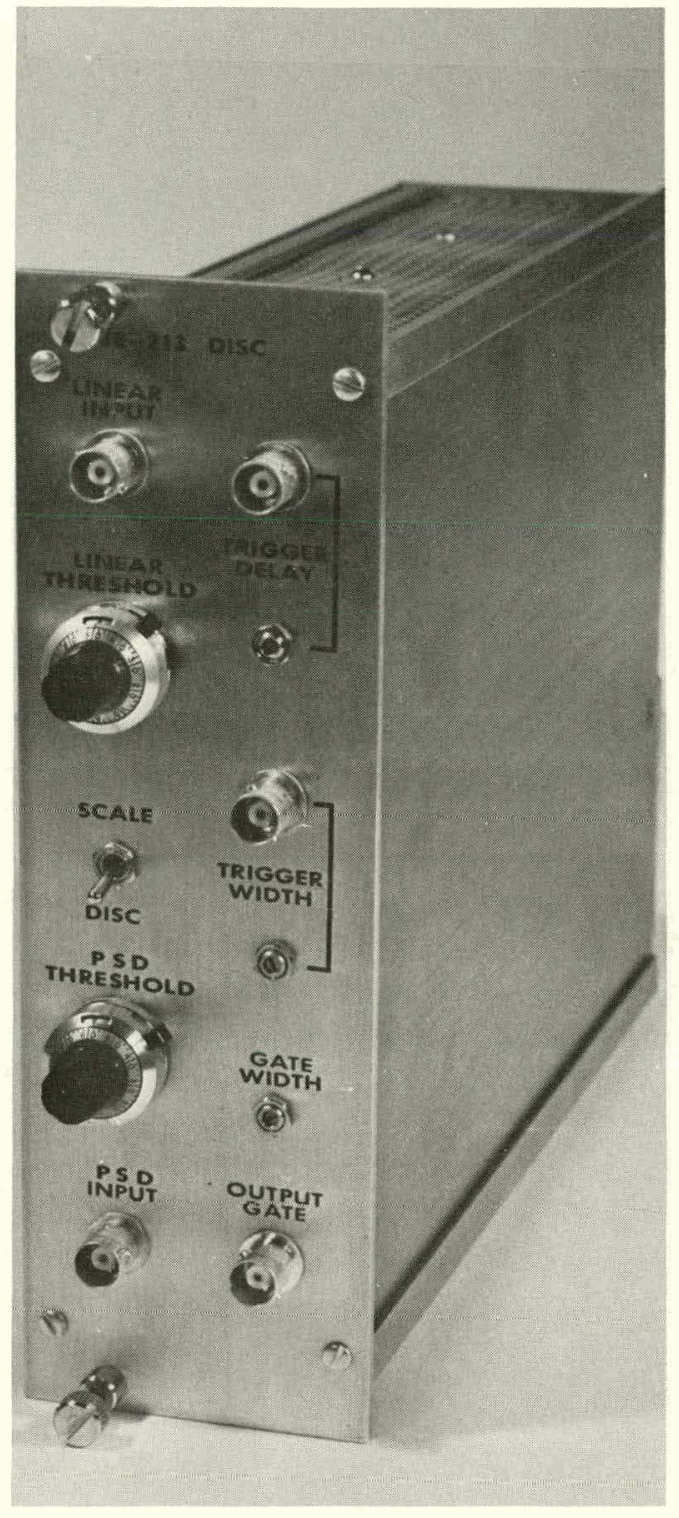

Fig. 8. Pulse Shape Discriminator (PSD) Circuit Diagram. ANL Neg. No. 103-Al1882. linear gates are gated on only for those pulses from the GNS circuit that represent a neutron induced event in the detector, provided the PSD mode switch is set to DISC (discriminate). When the mode switch is set to SCALE, either neutron or gamma-ray induced pulses will generate a gate signal. That is, coincidence timing is not required between the GNS and preamplifier output pulses in the SCALE mode.

Specifically, referring to the PSD circuit diagram shown in Fig. 9, the output of the double delay-line amplifier (Fig. 10-A) drives the input of discriminator $A_{1}$ causing single shot SS-1 to generate the pulse of Fig. 10-B. Single shot SS-2 is triggered on the fall of this pulse, thus generating the pulse shown in Fig. 10-C. The shaped and delayed GNS pulse (Fig. 10-D) drives discriminator $\mathrm{A}_{2}$ causing the output of gate 6 (Fig. 10-E) to go positive when the GNS pulse goes positive. The output pulse of single shot SS-2 is "ANDed" with the positive pulse of $10-\mathrm{E}$ at gate 7 , causing single shot SS-3 to trigger. The output of this single shot (Fig. 10$G)$ is used for gating the linear gate open. Transistors $Q_{1}, Q_{2}$, and $Q_{3}$ prevent retriggering of single shot SS-1 for approximately $10 \mu \mathrm{sec}$ following a previous trigger. This delay is used to provide pile-up rejection (when the PSD circuit is in the DISC mode) by preventing the linear gate from opening for pulses that follow a preceding pulse by less than $10 \mu \mathrm{sec}$.

\section{Double Delay-line Fast Amplifier}

The double delay-line fast amplifier is made up of a cascade of five operational amplifier stages as shown in Fig. 11. Amplifiers $A_{1}$ and $A_{2}$ in conjunction with delay lines $\mathrm{DL}_{1}$ and $\mathrm{DL}_{2}$ provide double delay differentiation which yields the crossover timing reference for the PSD module. One of the major design criterion for the amplifier was to optimize overload performance in order to achieve reliable timing characteristics at relatively high count rates, i.e., 3000 events/second. To this end, amplifiers $A_{1}$ and $A_{2}$ have unity closed loop gain and are DC coupled. 


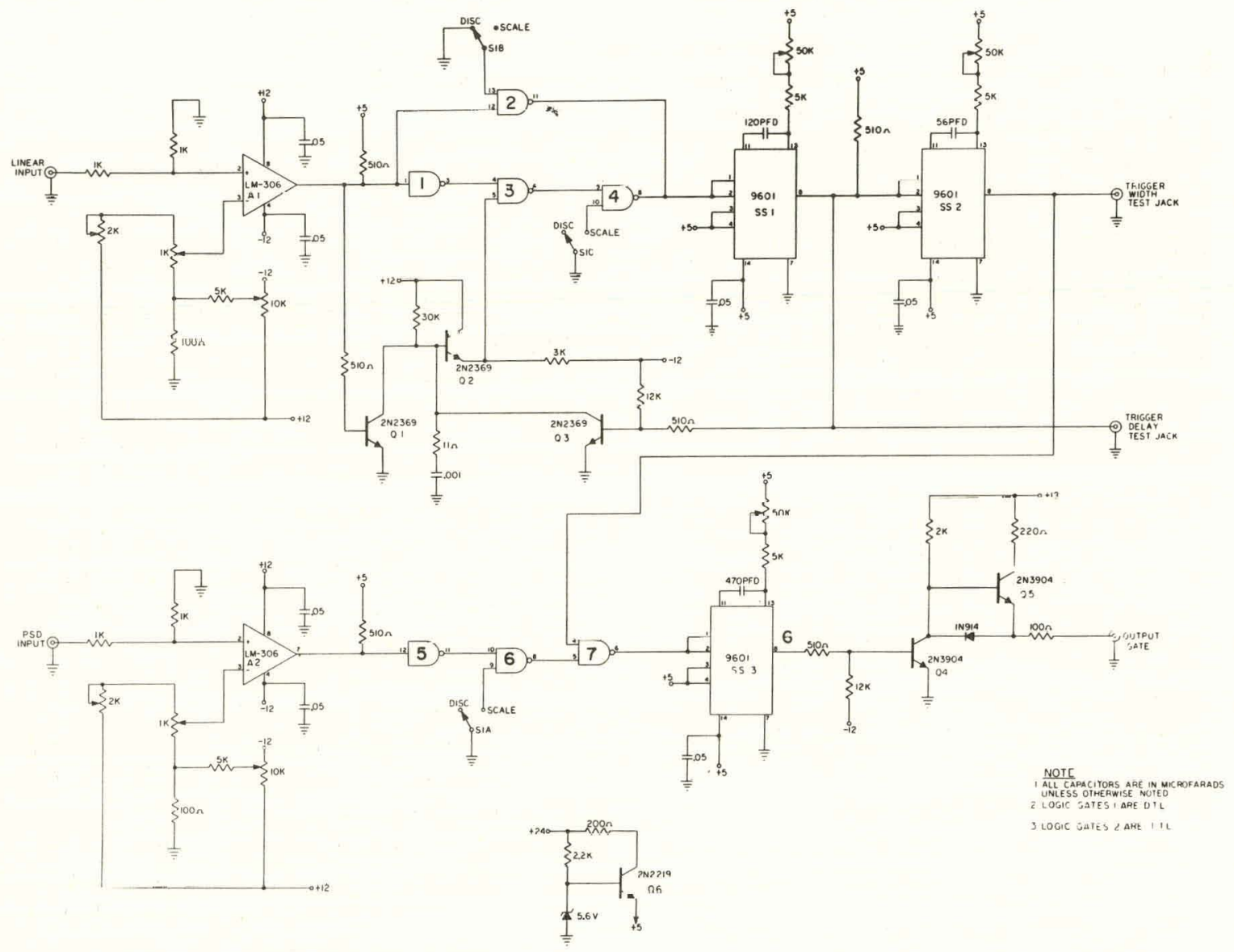

Fig. 9. Pulse Shape Discriminator (PSD) Circuit Diagram 


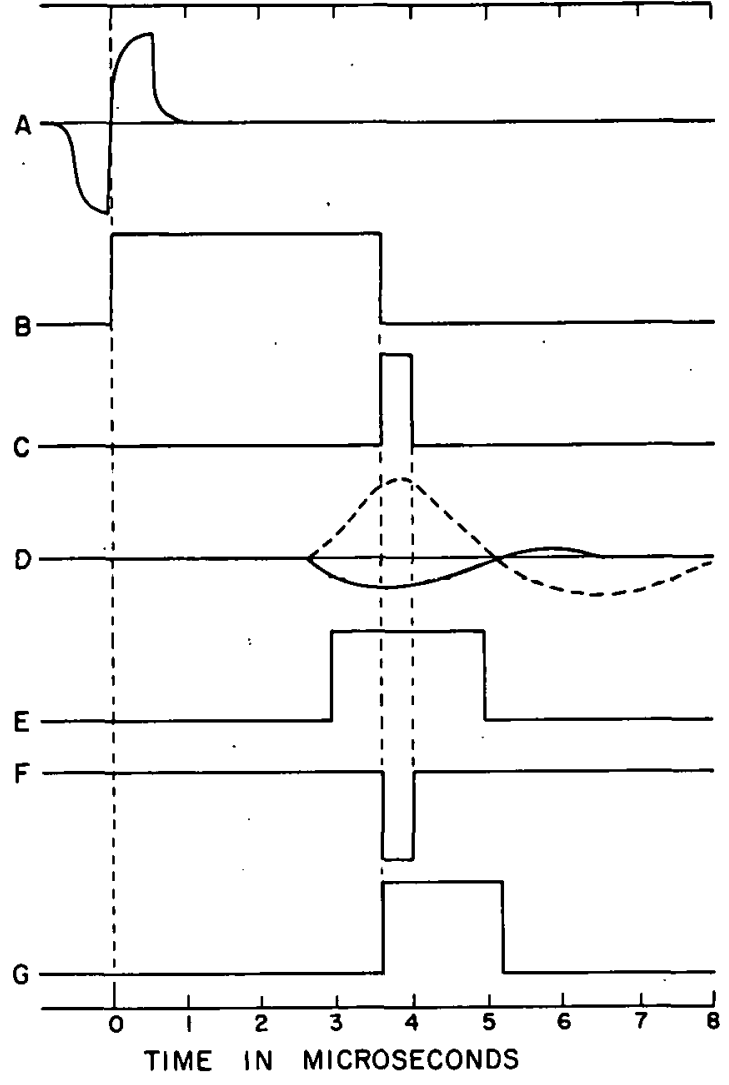

Fig. 10. Pulse Shape and Timing in the PSD Module
Amplifiers $A_{3}$ and $A_{4}$ provide a fixed gain of 20 each while $\mathrm{A}_{5}$ has a fixed gain of 10 . The course and fine gain is adjusted by the gain attenuating networks coupling $\mathrm{A}_{3}$ to $\mathrm{A}_{4}$ and $\mathrm{A}_{4}$ to $\mathrm{A}_{5}$.

\section{SPECTROMETER EVALUATION}

The operating characteristics of the spectrometer were evaluated using a ${ }^{22} \mathrm{Na}$ gamma-ray source, a $\mathrm{PuBe}$ neutron/gamma-ray source, and a $252 \mathrm{Cf}$ spontaneous fission source. These data were acquired with a specific objective in mind -- evaluate the performance of the system operating within the framework needed to complete accurate leakage measurements at the ZPPR. General operating limits were not established. Experiments could easily be performed to test the operation of this spectrometer for other experimental applications whose requirements fall outside the limits used in this evaluation.

Total count rates (neutron plus gamma-ray induced pulses) of nomin-

ally 3000 cps satisfied the above objective. At this count rate, pulse pileup effects were highly improbable. It was shown experimentally that no pileup distortions occurred in the pulse height spectra at $3000 \mathrm{cps}$. However, if the spectrometer were operated at a much higher count rate, it would be important to study this effect. Distortions in neutron spectra due to high count rates would result from both recoil-proton pulse pile up and additional recoill-electron pulses being gated into the spectrum. This latter effect can be explained, because superimposed recoil-electron pulses appear as a single pulse with an apparent slower decay time. Decrease in gamma-ray rejection as a function of count rate is shown in Fig. 12. The 3000 cps 1imit determined the minimum source-to-detector distance used for each experiment discussed in the remainder of this section.

\section{A. $\quad 22 \mathrm{Na}$ Gamma-ray Source Data}

A $10 \mu \mathrm{Ci}{ }^{22} \mathrm{Na}$ gamma-ray source was used to evaluate the resolution of this spectrometer, establish the energy calibrations, and set the gamma-ray rejection ratio. Fig. 13 shows the important portion of the $1.28 \mathrm{MeV}$ gammaray induced pulse-height distribution. As mentioned in Section II.A.3., Compton scattering predominates in this low $\mathrm{Z}$ detector material. Thus, the pulse height distribution from ${ }^{22} \mathrm{Na}$ gamma rays is the resolution broadened energy distribution of the Compton-scattered photons. 


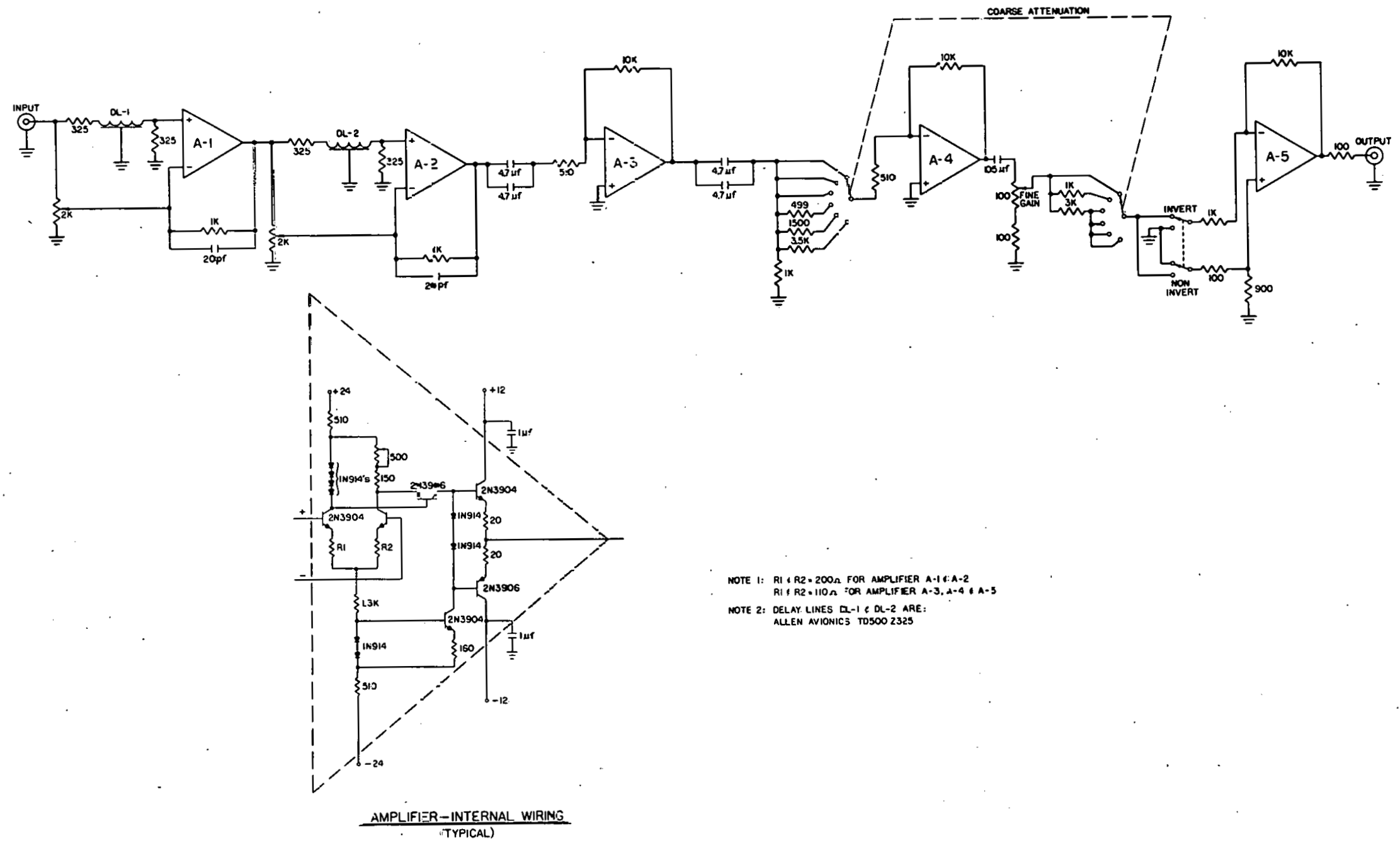

Fig: 11. Double Irelay Line Fast Amplifien Circuit Diagram 


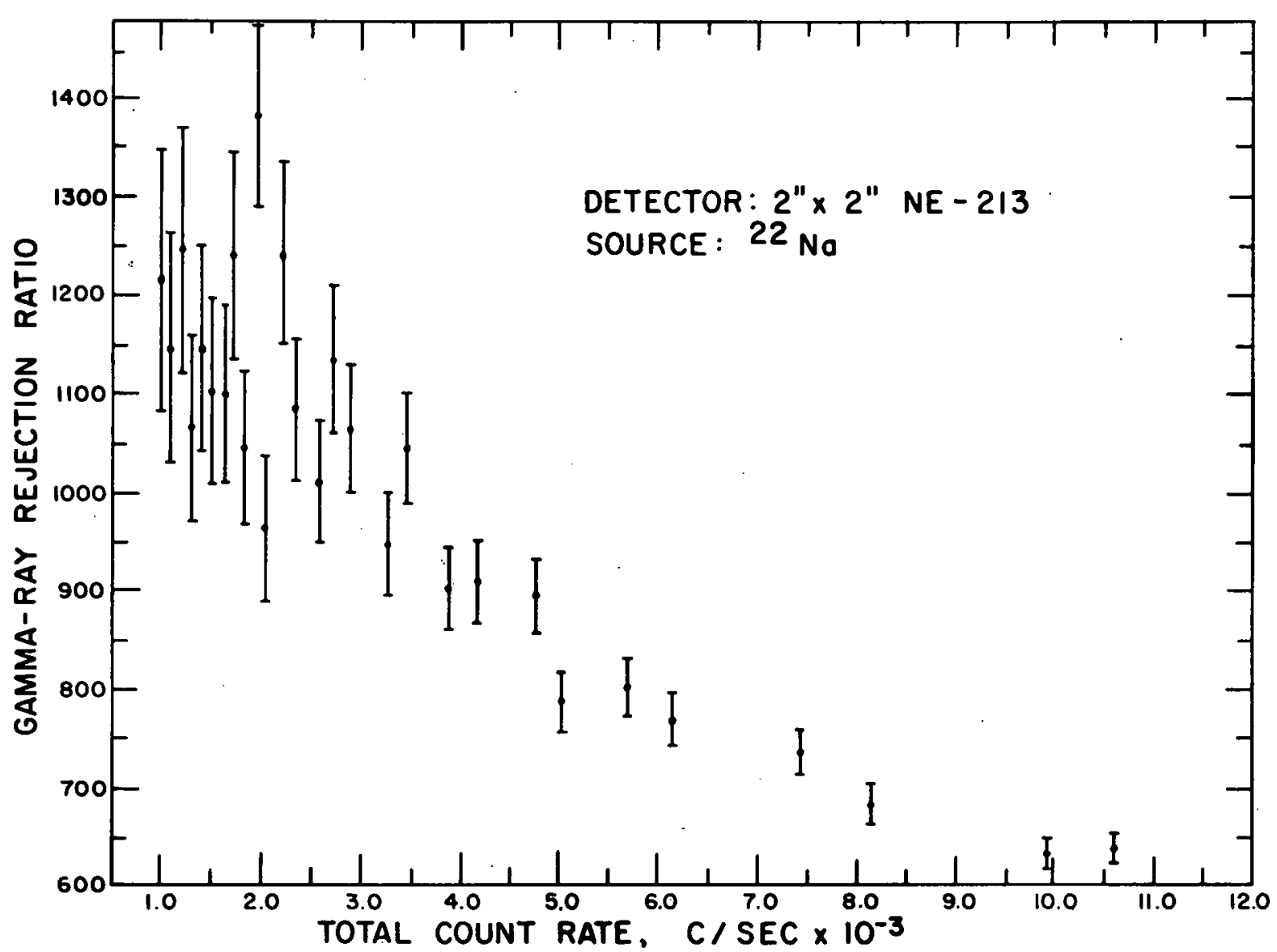

Fig. 12. Gamma-Ray Rejection Ratio as a Function of Countrate

Energy calibration of the raw proton-recoil data was determined relative to the $1.28 \mathrm{MeV}^{22} \mathrm{Na}$ gamma-ray distribution. The desired $\mathrm{keV} / \mathrm{channel}$ was achieved when half height of the Compton tail occurred exactly in channels 177 and 17.7 for the high- and low-gain data, respectively. Amplifier gain settings were set prior to each experiment using a precision pulser and by visual inspection of the raw ${ }^{2.2} \mathrm{Na}$ data. Gain shifts occurring during data acquisition were also checked following each experiment. However, this procedure did not always yield the desired accuracy. A computer code, FASTDATA [28], was written to mathematically transform the raw proton-recoil data to the proper $\mathrm{keV} / \mathrm{ch}$ annel. FASTDATA was designed to accept multiple ${ }^{22} \mathrm{Na}$ reference data for both high- and low-gain settings and the corresponding raw neutron-induced pulse-height data. The code produced both punched and printed output in the FERDOR input format.

Gamma-ray rejection measurements were made by accumulating ${ }^{22} \mathrm{Na-induced}$ pulses with the PSD module first in the SCALE mode and then in the DISC mode. SCALE mode operation corresponds to the number of total gamma-ray induced pulses arriving at the PSD input whose amplitude exceed the linear threshold. The data accumulated in the DISC mode corresponds to the number of those sametype pulses which trigger the PSD circuit and result in pulse height analysis 


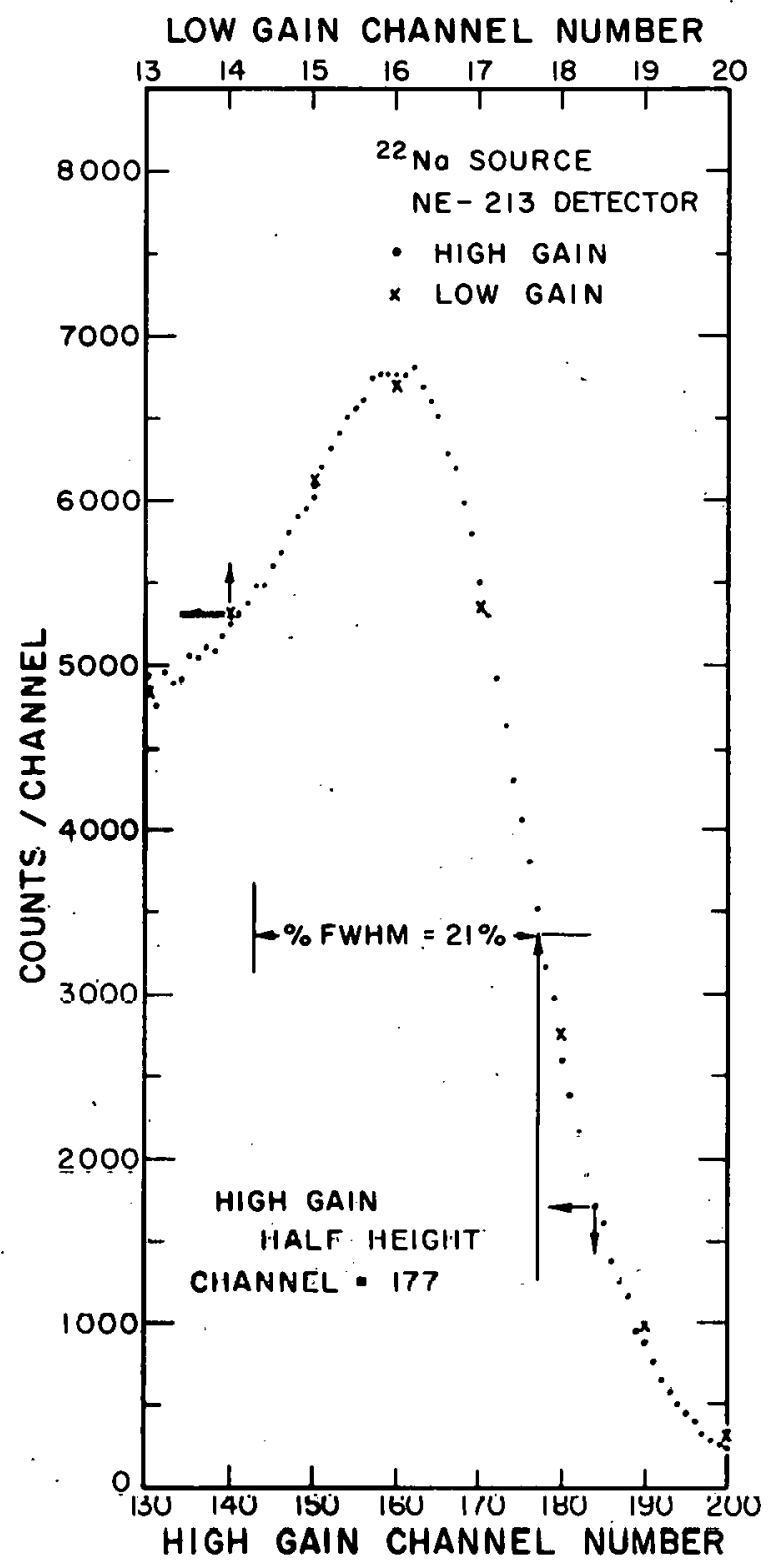

Fig. 13. High Energy Portion of the ${ }^{22} \mathrm{Na}$ Induced Pulse Height Distribution 
of gamma-ray induced pulses. The ratio of the results of these two experiments is precisely the gamma-ray rejection ratio.

\section{B. PuBe Neutron Spectra}

Measurement of PuBe neutron spectra provided a check on the energy calibration of the spectrometer system. Shape comparisons were not made since PuBe neutron spectra are dependent both on the source size and fabrication [5]. However, the spectral lines are reasonably well known. Spectral lines from one PuBe source measured with our system (an example is shown in Fig. 14) were compared to results reported by other investigators. Results of this comparison, consisting of measurements made by different techniques, are presented in Table I. The peak locations (energies of the spectral lines) of the AP-West data are in good agreement with the other data. Especially when it is noted that the FERDOR results are generated at from 0.1 to $0.2 \mathrm{MeV}$ intervals. That is, the binning operation in the unfolding process combines several channels of raw data.

C. $\quad{ }^{252} \mathrm{Cf}$ Neutron Spectra

Examination of measured ${ }^{252} \mathrm{Cf}$ neutron spectra was pursued to study the energy response of the spectrometer to fission-type spectra. Verification that the spectrometer could be used to measure the continuous differential flux of ${ }^{252} \mathrm{Cf}$ was important. This provided supporting evidence that the continuous-type high-energy neutron spectra measured at ZPPR would also be correct.

Reference ${ }^{252} \mathrm{Cf}$ data were accumulated with the detector assembly positioned in the center of a large room. The electronics were adjusted to provide a gamma-ray rejection ratio of 1000:1. Figure 15 shows a comparison of several ${ }^{252} \mathrm{Cf}$ spectrum measurements $[4,29,30]$. Each data set was normalized to unity area between 1.0 and $8.0 \mathrm{MeV}$. As shown, the AP-West reference spectrum was consistent with the other results.

To check the system response at different gamma-ray rejection ratios,

Cf spectra measurements were made at a rejection ratio of 150:1 and 1000:1. The spectrum for the 1000:1 setting was slightly lower below $1.2 \mathrm{MeV}$. Two obvious reasons exist which would explain this difference. First, fewer gamma-ray induced pulses were being analyzed as neutron-induced pulses. Or, some of the low energy neutron-induced pulses were lost using the higher rejection ratio. Above $1.2 \mathrm{MeV}$, no differences were evident. Since it was not critical for this application to extend the measurement below $1.2 \mathrm{MeV}$, no additional adjustments were made in the electronics in order to improve the data below $1.2 \mathrm{MeV}$.

To assure that the spectrometer system operated consistently and reproducibly, a comparison was made between ${ }^{252} \mathrm{Cf}$ spectrum measurements made 17 months apart. The two measurements were in excellent agreement. This indicated that pre-operational procedures, system set-up, and calibration techniques were adequate.

The conclusion is, after performing the above evaluation, that the spectrometer operated consistently and accurately over the energy range of approximately 1.2 to $10 \mathrm{MeV}$. The minimum possible lower energy limit was not estab- 


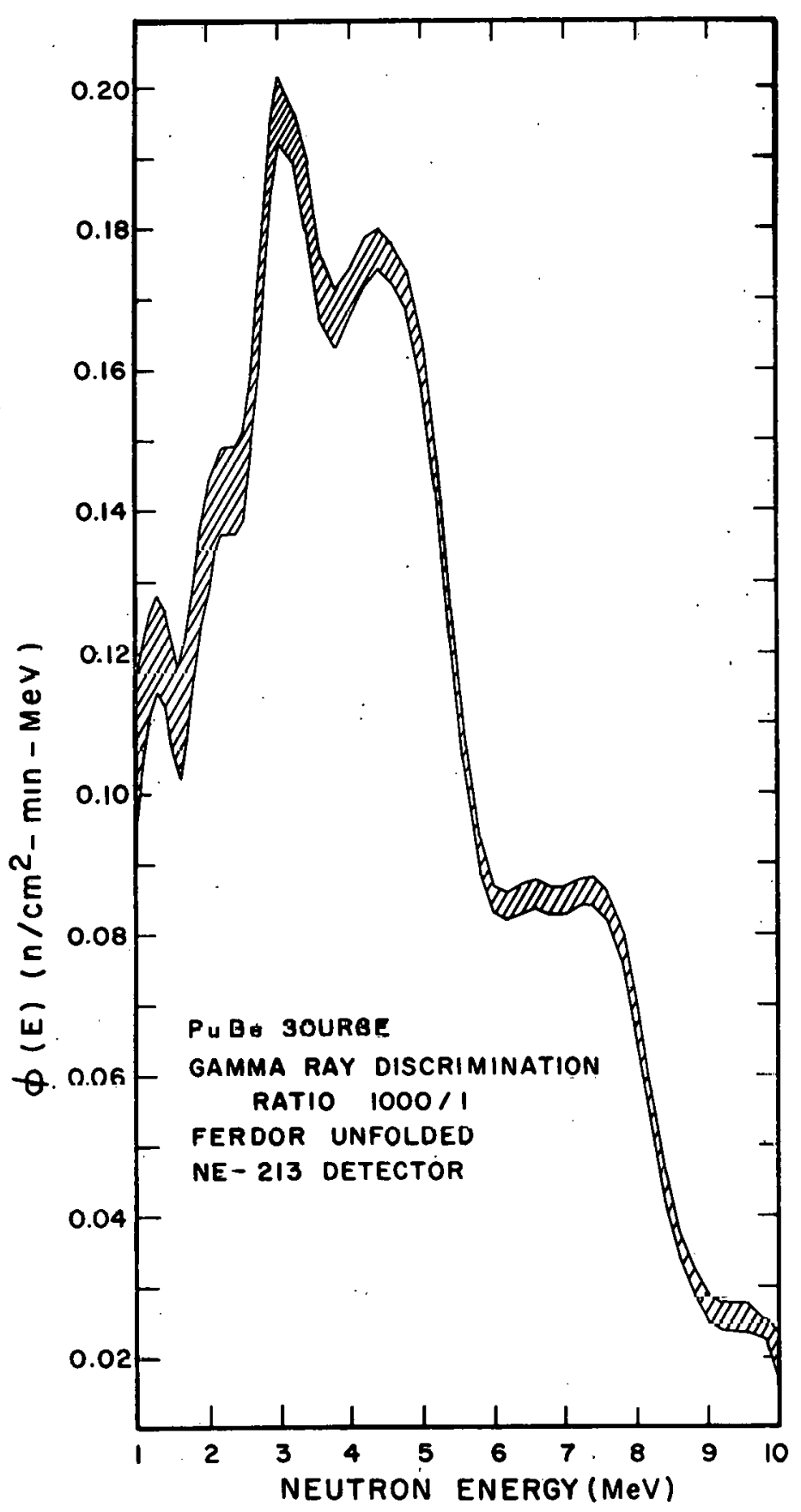

Fig. 14. PuBe Source Neutron Spectrum Measured under Ideal

Geometry Conditions 
TABLE I. Approximate ${ }^{\mathrm{a}}$ PuBe Neutron Spectrum Maxima (MeV)

\begin{tabular}{|c|c|c|c|c|c|c|}
\hline Organization & \multicolumn{2}{|c|}{ Monsanto } & UCLA & \multicolumn{2}{|r|}{ UMC } & ANL \\
\hline Reference & \multicolumn{2}{|c|}{5} & 32 & \multicolumn{2}{|r|}{11} & This report \\
\hline Detector Type & \multicolumn{2}{|c|}{ Stilbene } & $\begin{array}{l}\text { Ilford L4 } \\
\text { Nuclear } \\
\text { Emulsion }\end{array}$ & \multicolumn{2}{|r|}{$\mathrm{NE}-213$} & $\mathrm{NE}-213$ \\
\hline Detector Size & \multicolumn{2}{|c|}{$\begin{array}{l}20 \mathrm{~mm} \text { diam } \\
\times 10 \mathrm{~mm} \text { height }\end{array}$} & $\begin{array}{l}24.5 \mathrm{~mm} \times 76.2 \mathrm{~mm} \\
\times 600 \mu \mathrm{m} \text { thick }\end{array}$ & \multicolumn{2}{|c|}{$\begin{array}{l}51.6 \mathrm{~mm} \text { diam } \\
\times 63.5 \mathrm{~mm} \text { height }\end{array}$} & $\begin{array}{l}50.8 \mathrm{~mm} \text { diam } \\
\times \quad 50.8 \mathrm{~mm} \text { height } \\
\end{array}$ \\
\hline Unfolding Code & \multicolumn{2}{|c|}{ Not Specified } & $\mathrm{NA}$ & DUFOLD & FERDOR & FERDOR \\
\hline \multirow[t]{2}{*}{ Mass of $\mathrm{Pu}, \mathrm{g}$} & 2 & 160 & 80 & \multicolumn{2}{|c|}{ Not Specified } & 10. \\
\hline & $\begin{array}{l}-\overline{2} \\
2.2 \\
3.0 \\
-\overline{8} \\
4.8 \\
-\overline{7} \\
6.7 \\
7.8 \\
9.7\end{array}$ & $\begin{array}{l}-\overline{1} \\
1.9 \\
3.1 \\
-\overline{4} \\
\dot{4} .5 \\
--\overline{5} \\
6.6 \\
7.5 \\
9.5\end{array}$ & $\begin{array}{l}1.1 \\
2.3 \\
3.2 \\
-\overline{-} \\
4.8 \\
-- \\
-\overline{-} \\
7.8 \\
9.8\end{array}$ & $\begin{array}{l}1.3 \\
2.2 \\
3.3 \\
3.9 \\
4.7^{b} \\
5.2^{b} \\
6.7 \\
7.8 \\
9.6\end{array}$ & $\begin{array}{l}1.3 \\
-\overline{2}- \\
2.8 \\
-\overline{4} \\
4.2 \\
--\overline{6} \\
6.6 \\
7.2 \mathrm{~b} \\
9.2^{\mathrm{b}}\end{array}$ & $\begin{array}{l}1.3 \mathrm{~b} \\
2.2^{b} \\
3.1 \\
-\overline{-} \\
4.4 \\
--\overline{-} \\
6.6 \\
7.4 \\
9.6\end{array}$ \\
\hline
\end{tabular}

Location of spectral lines estimated from figures or tables reported in each reference.

b Shoulders, not resolved peaks. 


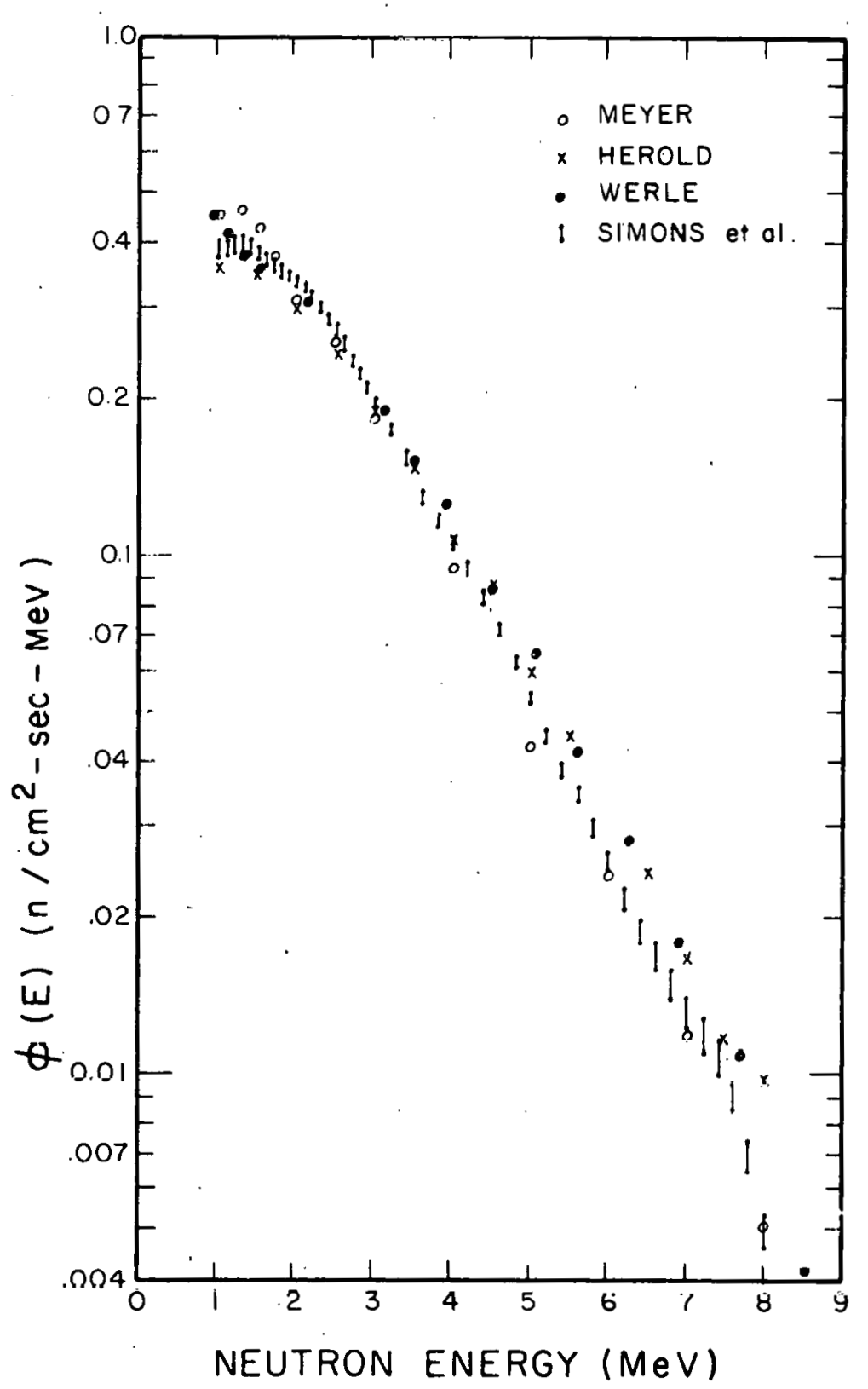

Fig. 15. Intercomparison of ${ }^{252} \mathrm{Cf}$ Neutron Spectra Measured with Different Spectrometers and Different Sources 
1ished. Likewise, the upper energy limit could be extended if necessary. For our application, 8-10 MeV was the maximum energy neutron present.

\section{RADIATION SHIELD/COLLIMATOR ASSEMBLY}

Spectra were measured in a beam extracted from the unshielded ZPPR by placing the detector inside a massive ( $170001 \mathrm{bs)}$ neutron and gamma-ray shield. This shield consisted of three main sections -- radiation shield, collimator, and beam shield cylinder. The radiation shield, shown in Fig. 16 in its full down position, was designed to house the NE-213 detector assembly. Its design, however, allows it to be used with a variety of detectors. A movable plug is located near the center of the shield. It is height adjustable so that the NE-213 detector assembly which sets on top of this plug, can be positioned along the centerline of the collimator opening. The plug can also be removed to accommodate insertion of a long detector from the bottom of the shield. Shielding materials would then be added around and below the long detector to prevent streaming radiation from reaching the detector. Before moving the shield into and out of the ZPPR cell, the steel "nose cone" was removed. Each part of the radiation shield was then moved separately. Raising and lowering of the shield was accomplished using jacks (not shown) bolted to each corner.

The collimator insert; shown in Fig. 17, was designed specifically for the 50.8-mm-diam cylindrical NE-213 detector. Its design was based on the fast-neutron collimator study reported by Straker [31]. Collimators for other applications could be easily designed, constructed, and inserted into the void region of the radiation shield.

A cylindrical beam shield plug, shown in its full down position in Fig. 18, was used to remove the primary neutron beam for background measurements. The plug composition was $304.8 \mathrm{~mm}$ of iron followed by $304.8 \mathrm{~mm}$ of lucite. This plug was raised and lowered remotely from the ZPPR control room.

The shielding properties of the device were measured in the ZPPR cell. The assembled shield was elevated to $1.53 \mathrm{~m}$, near the ZPPR radial core centerline, as shown in Fig. 18. At this detector-to-radial reflector position of $2.9 \mathrm{~m}$, the neutron shielding characteristics of the device were excellent. For example, with the reactor operating at 65 watts, a power characteristic of that required for leakage spectrum measurements, the ratio of the recorded neutron-induced pulses with the beam shield cylinder down to the number with the cylinder up was 0.0054 . This measurement was completed using a pulseheight range corresponding to a neutron energy span of 1 to $10 \mathrm{MeV}$.

A comparison of ${ }^{252} \mathrm{Cf}$ spectra measured with the detector assembly located inside and outside of the shield/collimator assembly is shown in Fig. 19. As shown, the detector shielded result is lower below $1.4 \mathrm{MeV}$. One possible explanation for this is that room scattered neutrons were completely removed using the shielded configuration. Collimator lip scatter did not appear to be a problem. 
3 BORATED POLYETHYLENE

$\square$ STEEL $\quad-\rightarrow$ LEAD

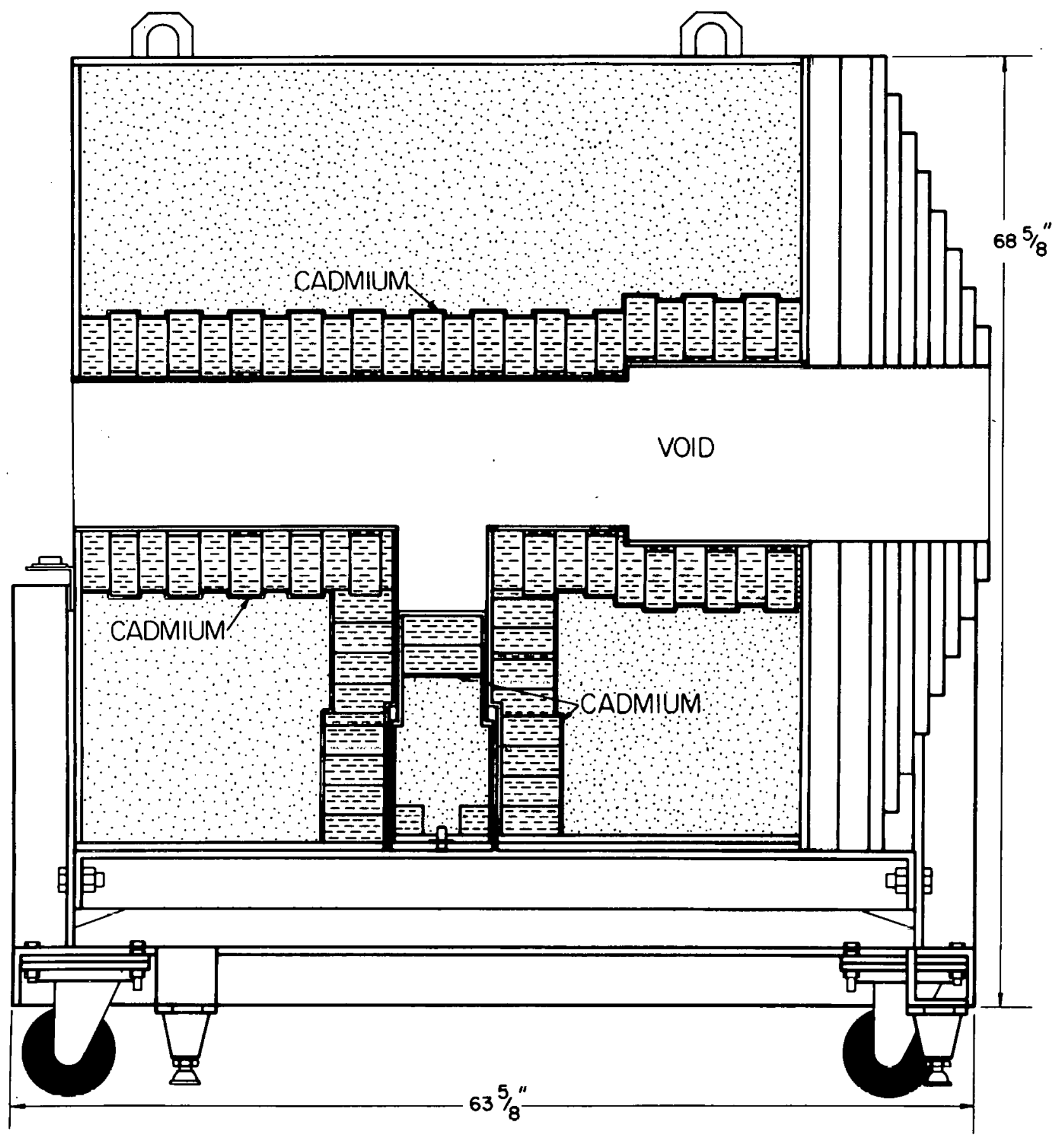

Fig. 16. Schematic Drawing of Radiation Shield. ANL Neg. No. 103-B11415. 


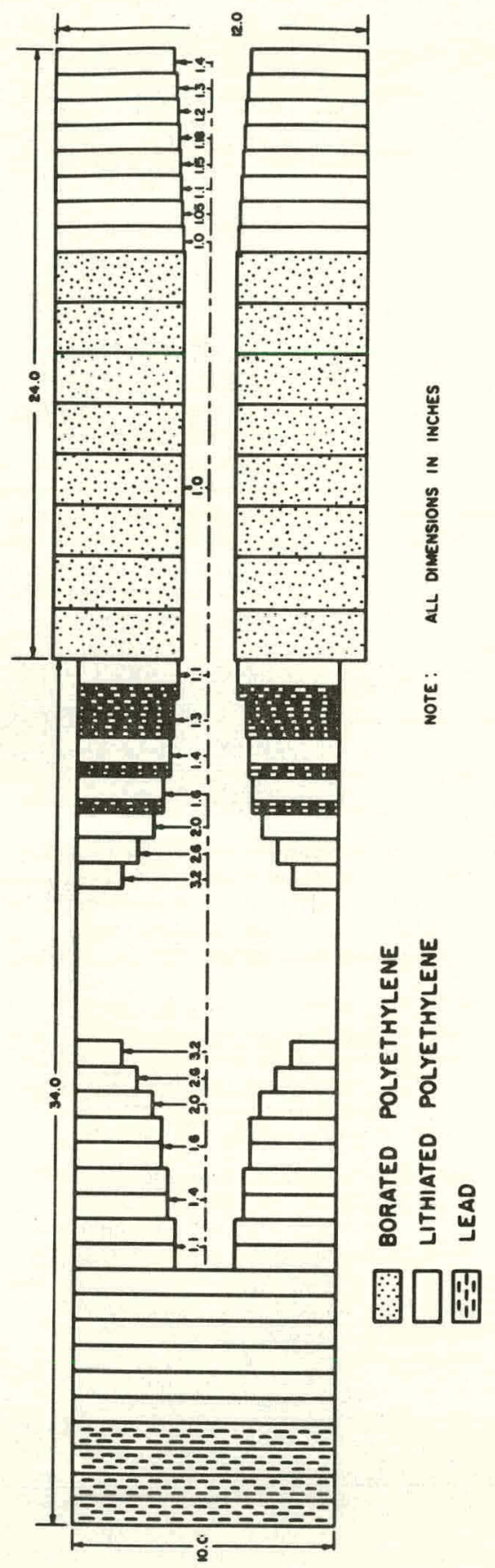

Fig. 17, Schematic Drawing of Collimator Insert for the Radiation Shield. ANL Neg. No. 103-B11416. 


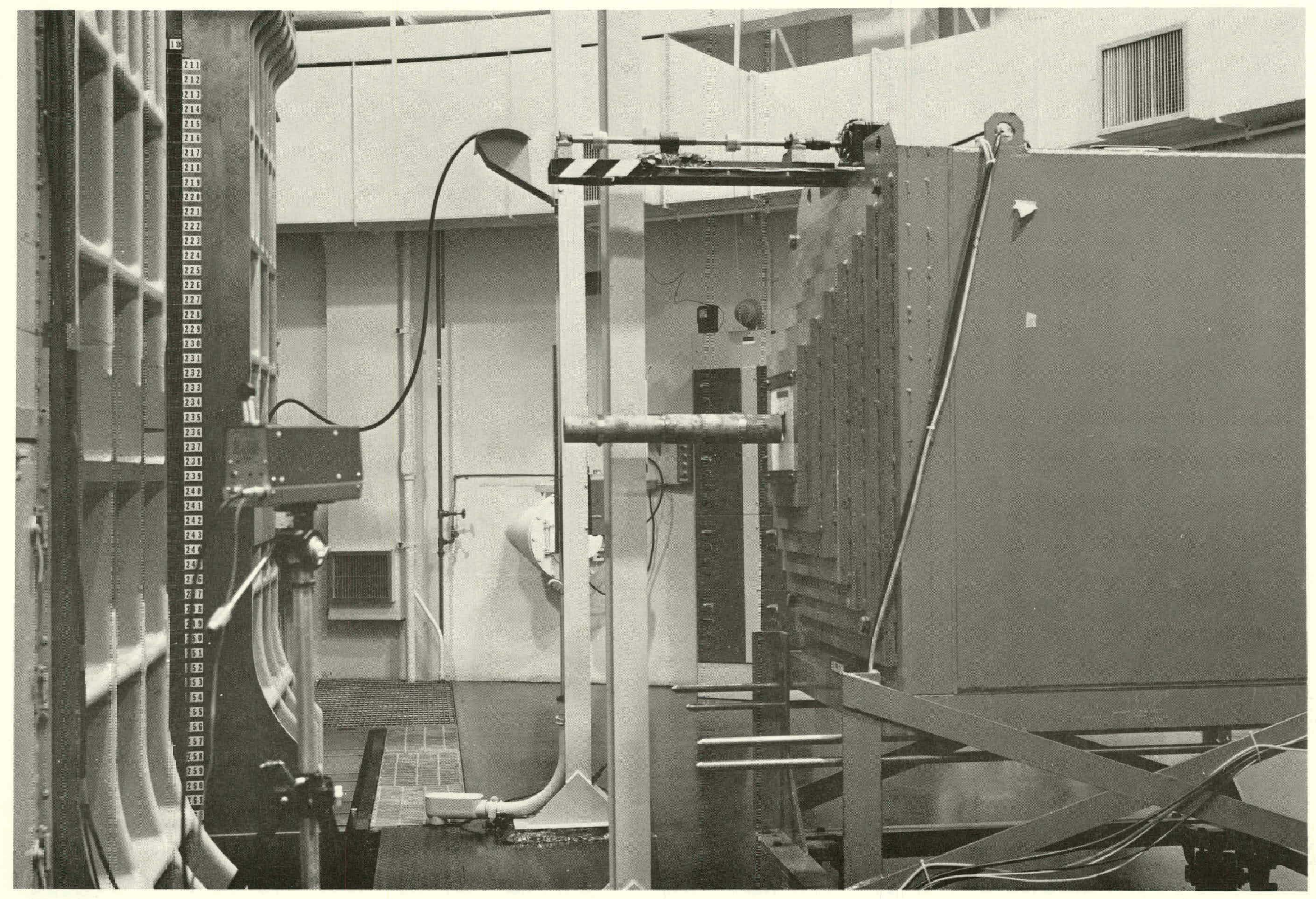

Fig. 18. Shield/Collimator in the ZPPR Cell. ANL Neg. No. 10ミ-BI1424. 


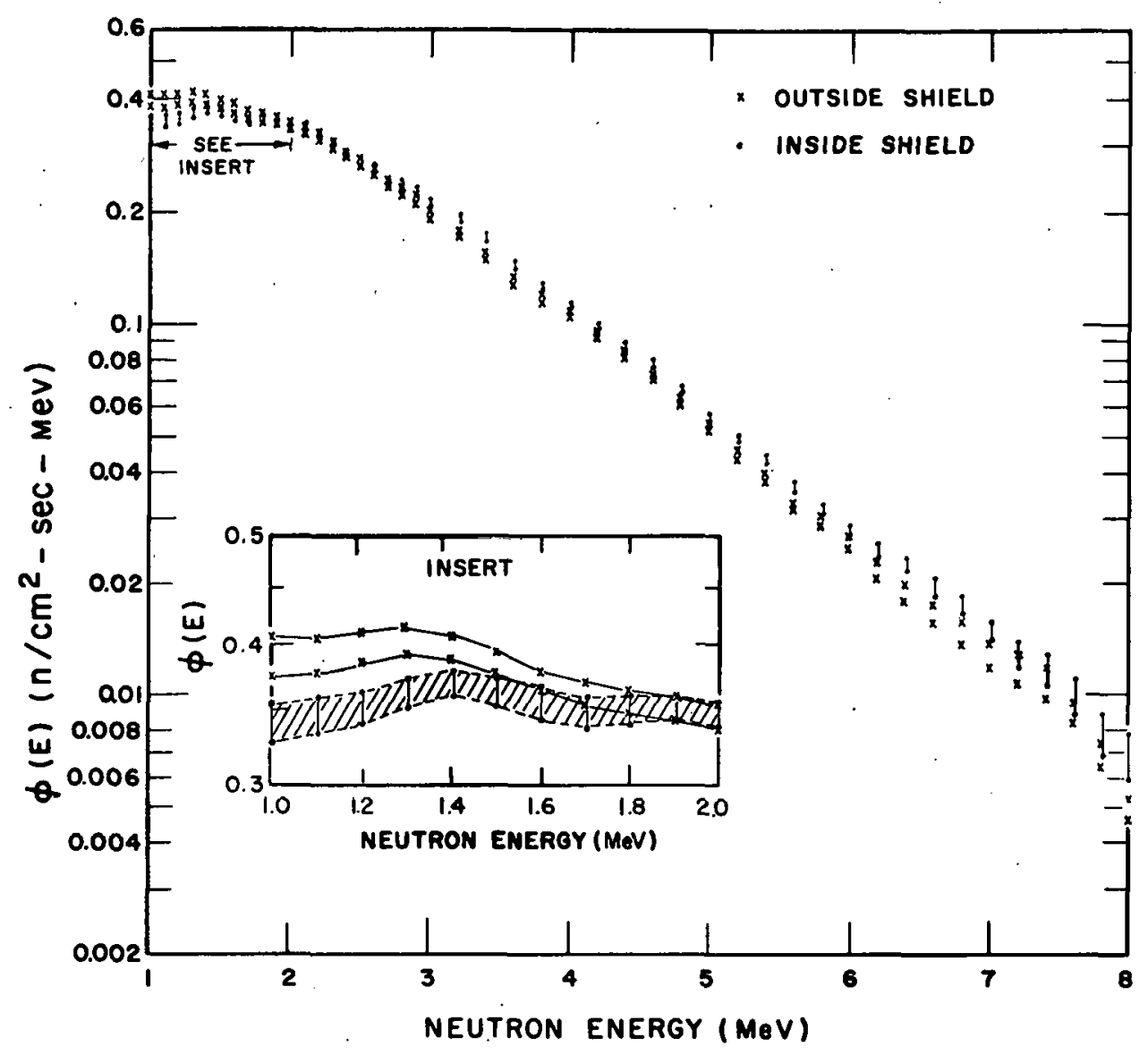

Fig. 19. Comparison of ${ }^{252}$ Cf Neutron Spectra Measured with the Detector Located Inside and Outside the Shield/Collimator

\section{ZPPR FAST NEUTRON LEAKAGE MEASUREMENTS}

Extracted-beam-type neutron spectra were measured at ZPPR with the shield/collimator aligned near the axial half-height of the reactor. Special tunnel fuel plates were used in the reactor to produce a hole of either 15.9 or $25.4 \mathrm{~mm}$ in diameter exiting through a $50.8 \mathrm{~mm}$ opening in the radial support structure of the reactor. Additional collimation in the form of a steel and polyethylene pre-collimator with a $25.4 \mathrm{~mm}$ square hole, was placed near the reactor to eliminate neutrons originating from the outer edge of the radial reflector. The pre-collimator was placed directly in the path between the beam hole and shield/collimator assembly. This geometry allowed for background measurements by using the beam plug discussed previously in Section IV.

Leakage neutron spectra studies were performed on ZPPR assemblies 3 and 4. Evaluation of the operating characteristics of the spectrometer was performed on ZPPR assembly 3. Moderate data acquisition times were used to obtain information on the relative neutron to gamma-ray background, the relative neutron to gamma-ray $f l u x$ in the extracted beam, the optimum reactor power, and the approximate neutron spectrum ahove $1 . \mathrm{MeV}$. These results showed that the spectrometer could be used to measure leakage neutron spectra above $1 \mathrm{MeV}$ 
at any radial position. (along matrix row 137) in ZPPR. One day per measurement would be required with the reactor operating at a nom inal power of 50 watts.

More precise measurements were then made with beams extracted from the inner core, outer core, and radial blanket on ZPPR assembly 4, phase 2. The FERDOR unfolded results of these measurements are shown in Figs. 20-22. The outer core spectrum contains oscillations at high energies inherent in unfolding poor statistical data. This measurement was made simultaneously with a gas-filled proportional counter spectrum measurement. As shown in Fig. 21, the integrated power for this run was very low, only 8.4 watt hours. Inner core and radial blanket spectrum measurements were each completed within one day at power levels of 50 and 75 watts respectively. These two spectra accurately describe the leakage spectrum from the core and blanket.

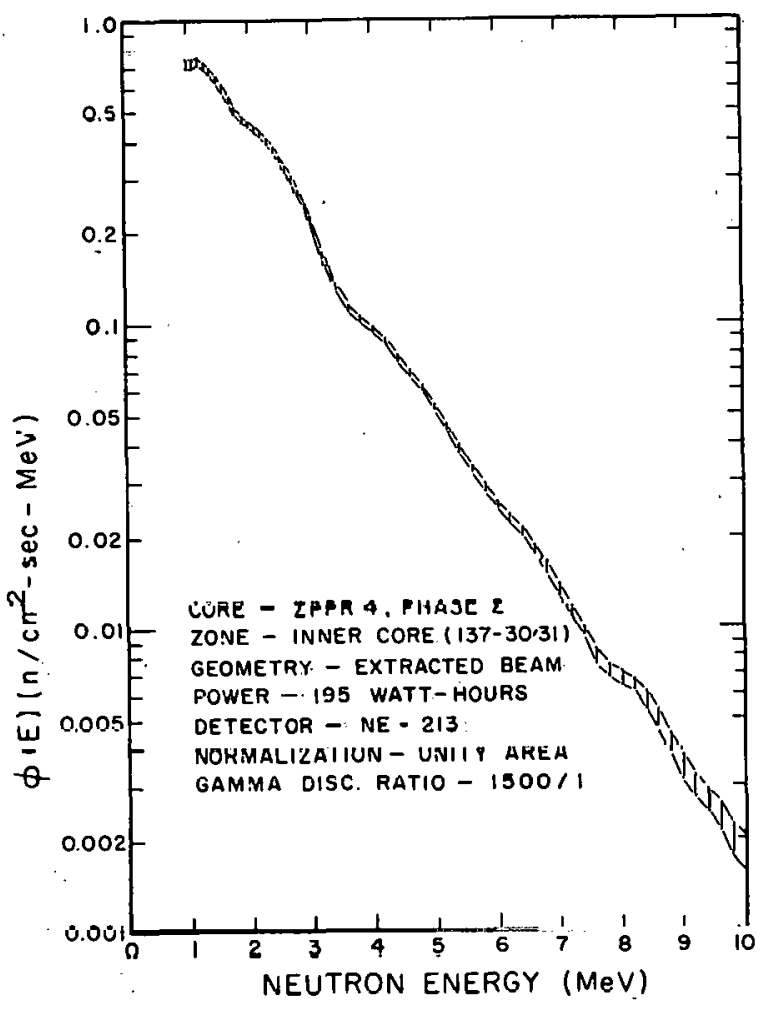

Fig. 20. Measured Neutron Spectrum from the Inner Core Zone Normalized to Unity Area from 1.4 to $7.8 \mathrm{MeV}$ 


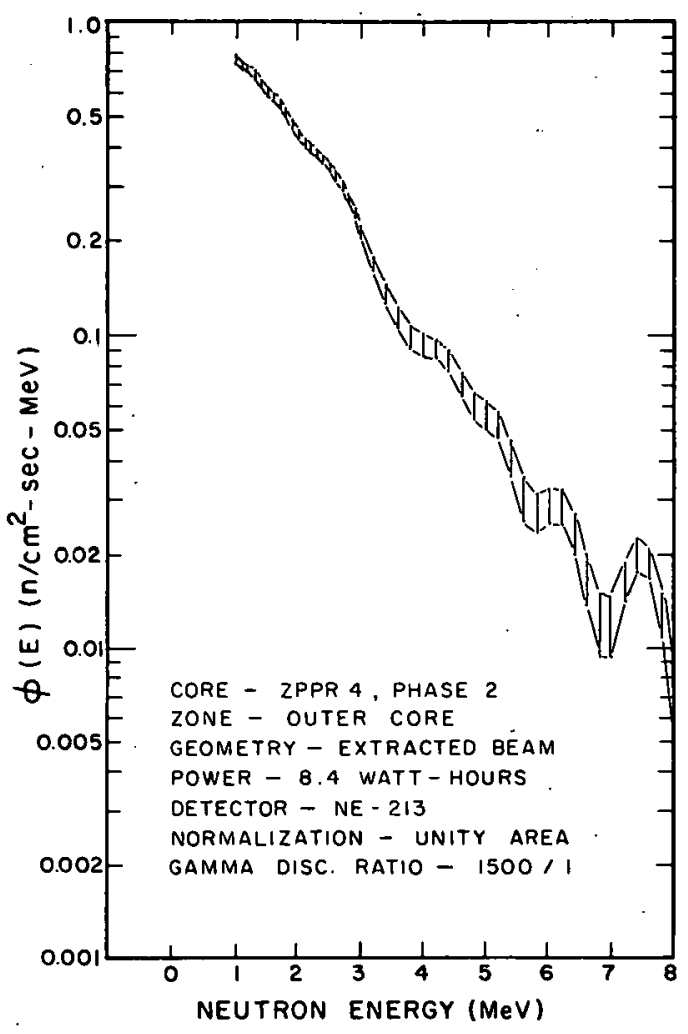

Fig. 21. Measured Neutron Spectrum from the Outer Core Zone Normalized to Unity Area from 1.4 to $6.8 \mathrm{MeV}$

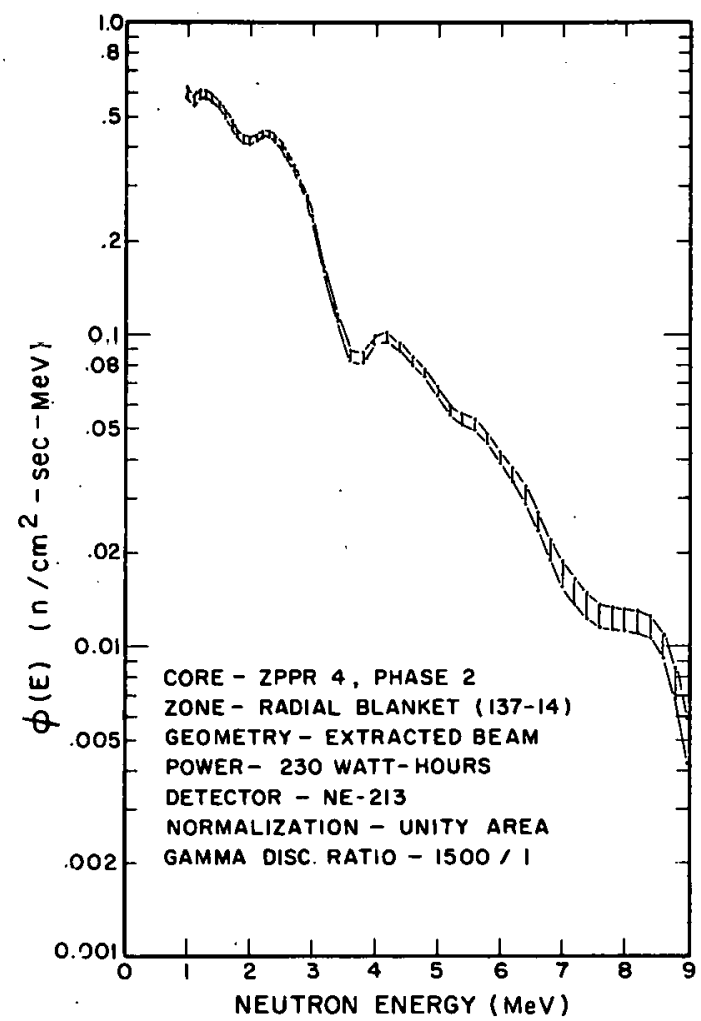

Fig. 22, Measured Neutron Spectrum from the Radial Blanket Zone Normalized to Unity Area from 1.4 to $7.8 \mathrm{MeV}$ 


\section{REFERENCES}

1. G.E. Hansen, R.K. Smith, and G.G. Simons, "Geometrical Efficiency Equation for Proton Recoil Telescopes," Nucl. Sci. Eng., 61, 269-276 (Oct. 1976).

2. E.F. Bennett, "Fast Neutron Spectroscopy by Proton-recoil Proportiona1 Counting, "Nucl. Sci. Eng., 27, 16-27 (1967).

3. E.M. Broomfield and M.D. Carter, "Proton Recoil Counter Techniques in ZEBRA," AEE Winfrith, AEEW-M-905 (1969).

4. H. Werle and H. Bluhm, "Fission-neutron Spectrum Measurements of $235^{\mathrm{U}}$, ${ }^{239} \mathrm{Pu}$, and ${ }^{252} \mathrm{CF}$," Journal of Nucl. Eng., 26, 165-176 (1972).

5. M.E. Anderson and R.A. Neff, "Neutron Energy Spectra of Different Size ${ }^{239}$ Pu-Be Sources," Trans. Am. Nucl. Soc., 11, 454 (Nov. 1968).

6. M.N. 'lhompson and J.M. Taylor, "Neutron Spectra From AmBe and RaBe Sources," Nucl. Inst. Meth., 37, 305-308 (1965).

7. F. DeGuarrini, "Two Different Technique Measurements of the Neutron Spectrum of an AmBe Source," Nucl.. Inst. Met.h., 92, 277-284 (1971).

8. V.V. Verbinski, W.R. Burrus, T.A. Love, W. Zobe1, N.W. Hill, and R. Textor, "Calibration of an Organic Scintillator for Neutron Spectrometry," Nucl. Inst. Meth., 65, 8-25 (1968).

9. G.G. Simons, "Development, Calibration, and Utilization of the KSU NE-213 Fast neutron Spectrometer," PhD. thesis, Kansas State University, Manhattan (1968).

10. G.G. Simons; "Liquid Organic Fast-neutron Spectrometer," Argonne Nat1onal Laboratory, ANL-7610, 434-437 (Jan. 1970).

11. W. Meyer and W.H. Miller, "Dcvclopment and Standardization of the UMC NE-213 Liquid Scintillation Proton Recoil Fast Neutron Spectrometer System," University of Missouri - Columbia Report NSF-GK-40728-UMC-2 (Feb. 1975).

12. Donald Shook, "A Small Differential Liquid Scintillator Neutron Spectrometer," Lewis Research Center, NASA-TM-X-52828 (June 1970).

13. G.G. Simons, R.J. Forrester, and P.J. Price, "Neutron Spectrum in Central Rodded Zone of ŻPPR Assembly 2," Argonne National Laboratory, ANL-8010, 188-189 (Jan. 1975).

14. W.P. Bucher and C.E. Hollandsworth, "Pulse-shape Anisotropy in the Scintillation Response of Stilbene," Nuclear Effects Laboratory, BRL-R-1474 (Feb. 1970).

15. G.G. Simons et al, "Measured NE-213 Fast-neutron Spectrometer Response Functions and Absolute Efficiency," Trans. Am. Nucl. Soc., 11, 704-705 (Nov. 1968). 


\section{REFERENCES (cont.)}

16. J.B. Birks, "The Scintillation Process in Organic Systems," I.R.E. Trans. Am. Nucl. Soc., NS-7 No. 2, 2-11 (1960).

17. R.E. Textor and V.V. Verbinski, "005: A Monte Carlo Code for Calculating Pulse Height Distributions Due to Monoenergetic Neutrons Incident on Organic Scintillators," Oak Ridge National Laboratory, ORNL-4160 (Feb. 1968).

18. S.N. Cramer, "Monte Carlo Analysis of an NE-213 Detector," Oak Ridge National Laboratory, ORNL-TM-4149 (Mar. 1973).

19. W.R. Burrus and V.V. Verbinski, Nucl. Inst. Meth., 67, 181-196 (1969).

20. G.A. Mutone and W. Meyer, Nual. Inst. Meth., 106, 445-452 (1972).

21. Martin Sperling, "Spectral Unfolding: Its mathematical Basis, Implementation and Application with MAZE 2," Science Applications, DNA2990F (SAI-72-574-LJ) (Oct. 1972).

22. M.E. Toms, Nucl. Inst. Meth., 92, 61-70 (1970).

23. A.A. O'Dell, C.W. Sandifer, and R.B. Knowlen, "Neutron Counting Efficiency and Charged Particle Response of an NE-213 Fluor Detector," EG and G, Inc., UC-2, EGG-1183-2172 (Jan. 22, 1968).

24. R.B. Owen, "Pulse Shape Discrimination - A Survey of Current"Techniques," I.R.E. Trans. Nucl. Sci., NS-9, No. 2, 285-293 (1962).

25. J.M. Larson, "A Wide-band Charge-sensitive Preamplifier for Protonrecoil Proportional Counting," Argonne National Laboratory, ANL-7 17 . (1969).

26. M. Forte, A. Konsta, and C. Maranzana, "Electronic Methods for Discriminating Scintillation Shapes," Proc. Int. Conf. on Nuclear EZectronics, Belgrade, May 15-20, 1961, Vo1. 2, 277-286 (1962).

27. "COOLC/FERDOR Spectra Unfolding Codes," Oak Ridge National Laboratory, RSIC Computer Code Collection, PSR-17 and PSR-18.

28. R.S. Reynolds, Miss. State Univ., unpublished information (1975).

29. W.Meyer, "Californium-252 Fast-neutron Reference Spectra," Trans. Am. Nucl. Soc., 19, 480 (1974).

30. T.R. Herold, "Neutron Spectra from Californium-252 Wire Sources," Savannah River Laboratory, DP-1322 (March 1973).

31. E.A. Straker, "Fast-neutron Collimator Studies: The TSF-SNAP Core Mapping Collimator," Nucl. Appl., 6, 168-174 (Feb. 1969).

32. R.L. Lehman, "The Origin of Neutron Groups in $B e(\alpha, n)$ Sources," Nucl. Thist. Meth., 6n, 253-2.6ก (1968). 
Distribution for ANL-77-58

Internal:

J. A. Kyger

A. Amorosi

R. Avery

L. Burris

D. W. Cisse 1

S. A. Davis

B. R. T. Frost

D. C. Rardin

R. G. Staker

R. J . Teunis

C. E. Till

R. S. Zeno

C. E. Dickerman

H. K. Fauske

S. Fistedis

B. D. Lallar

J. F. Marchaterre

H. U. Monsion

R. Sevy

G. T. Garvey

D. C. Price

M. Abdou

P. I. Amund son
R. J. Armani

E. F. Bennett

R. A. Beyerlein

S. K. Bhattacharyya

M. M. Bretscher

J. Brooks

R. G. Bucher

S. G. Carpenter

C. E. Cohn

R. J Cornella

S. A. Cox

L. R. Dates

R. J. Forrester

K. E. Freese

J. M. Gasidlo

B. W. Gnin

T. S. Huntsman

R. E. Kaiscr

J. M. Larson

L. G. Iesage.

F. E. LeVert

R. A. Lewis

G. Lowe

D. W. Maddison
F. H. Martens

H. F. McFarlane

J. Morman

N. O'Fallon

D. N. Olsen

I. K. 01son

P. J. Persiani

R. B. Pond

K. G. Porges

W. R. Robinson

G. K. Rusch

R. A. Scharping

G. G. Simons (20)

A. B. Smith

v. M. Smieh

W. J, Sturm

F. W. Thalgott

T. J. Yule

C. Baker

A. B, Krisciunas

ANL Contract File

ANL Libraries (5)

TIS Files (6)

\section{Externa1:}

ERDA-TIC, for distribution per UC-79d (264)

Manager, Chicago Operations Office

Chief, Chicago Patent Group .

President, Argonne Universities Association

Director, ERDA-RDD. (2)

Director, Reactor Programs Div., ERDA-CH

Director, CH-INEL

Applied Physics Division Review Committee:

P. Grecbler, General Electric Co., Sunnyvale

R. L. Hellens, Combustion Engineering, Inc.

J. M. Hendrie, Brookhaven National Laboratory

W. B. Loewenstein, Electric Power Research Institute

D. B. Wehmeyer, Detroit Edison Co.

S. A. Werner, Univ. Missouri 